pag

Business School

WORKING PAPER SERIES

\begin{tabular}{c|l} 
Working Paper & $\begin{array}{l}\text { Dynamic spillovers among major energy } \\
\text { and cereal commodity prices }\end{array}$ \\
$2014-160$ & $\begin{array}{l}\text { Walid Mensi } \\
\text { Shawkat Hammoudeh } \\
\text { Duc Khuong Nguyen } \\
\text { Seong-Min Yoon }\end{array}$ \\
\end{tabular}

http://www.ipag.fr/fr/accueil/la-recherche/publications-WP.html

IPAG Business School

184, Boulevard Saint-Germain

75006 Paris

France

IPAG working papers are circulated for discussion and comments only. They have not been peer-reviewed and may not be reproduced without permission of the authors. 


\title{
Dynamic spillovers among major energy and cereal commodity prices
}

\author{
Walid Mensi ${ }^{\mathrm{a}}$, Shawkat Hammoudeh ${ }^{\mathrm{b}, *}$, Duc Khuong Nguyen ${ }^{\mathrm{c}}$, Seong-Min Yoon ${ }^{\mathrm{d}, 1}$ \\ ${ }^{a}$ Department of Finance and Accounting, El Manar University, B.P. 248, C.P. \\ 2092, Tunis Cedex, Tunisia \\ Emails: walid.mensi@fsegt.rnu.tn \\ ${ }^{b}$ Lebow College of Business, Drexel University, Philadelphia, PA 19104-2875, \\ United States \\ Email:hammousm@drexel.edu \\ ${ }^{c} I P A G$ Lab, IPAG Business School, 184 Boulevard Saint-Germain, 75006 Paris, \\ France \\ Email: duc.nguyen@ipag.fr \\ ${ }^{d}$ Department of Economics, Pusan National University, Busan 609-735, Republic \\ of Korea \\ Email: smyoon@pusan.ac.kr
}

\begin{abstract}
Over the past decade, the sharp increases in the prices of oil and agricultural commodities have raised serious concerns about the heightened volatility of these markets and the possible negative interactions between them. This article deals with the dynamic return and volatility spillovers across internationally traded energy and cereal commodity markets. It also examines the impacts of three types of OPEC news announcements on the volatility spillovers and persistence in these markets. For this purpose, we make use of the VAR-BEKK-GARCH and VAR-DCC-GARCH models for the daily prices of eight major commodities including WTI oil, Europe Brent oil, gasoline, heating oil \#2, barley, corn, sorghum, and wheat. Our results provide evidence of significant linkages between the energy and cereal markets. Moreover, the OPEC news announcements are found to exert influence on the oil markets as well as on the oil-cereal relationships. Finally, we show that the persistence of volatility decreases (increases) for the crude oil and heating (gasoline) returns after accounting for the OPEC announcements in these multivariate GARCH models. However, the results are more mixed for the cereal markets. Overall, our results can be used to improve the risk-adjusted performance by having more diversified portfolios and also serve to hedge the oil risk more effectively.
\end{abstract}

JEL classification: G14; G15.

Keywords: Cereal, Energy, OPEC meetings, Volatility spillovers, Multivariate GARCH.

* Corresponding author. ' Lebow College of Business, Drexel University, 3141 Chestnut Street, Philadelphia, PA 19104-2875. Email: hammousm@drexel.edu. Fax: (215) 895-6975.

\footnotetext{
${ }^{1}$ The fourth author (S.M. Yoon) is grateful for the financial support from the National Research Foundation of Korea in a grant funded by the Korean Government (NRF-2011-330-B00044).
} 


\section{Introduction}

The growing interest in research on the price and volatility dynamics of energy and agricultural commodity markets has attracted more attention following the recent surges in both the energy and food prices. Moreover, the energy and agricultural commodity prices have also experienced long swings and sharp fluctuations over the last decade, which are likely to be driven more by changes in macroeconomic uncertainties, economic and financial crises, and regulations to combat dangerous climate warming. Recent statistics show that international nominal prices of all major food commodities reached their highest levels in nearly 50 years during the first quarter of 2008. These unprecedented increases in prices of commodities, coupled with substantial increases in their volatility, reflect uncertain markets and volatile environment. ${ }^{2}$ Sumner (2009) shows that the percentage price increases for grains from 2006 through mid-2008 are among the largest changes in the agricultural commodity history. According to the International Grains Council (IGC), a dramatically increased trend in cereal prices is observed during the period 2000-2008, particularly during the 2007-2008 food crisis. ${ }^{3}$

The recent spikes in agricultural commodity prices can be explained by at least three factors. ${ }^{4}$ First, the energy and agricultural prices have become increasingly intertwined. Biofuels can be derived from agricultural commodities. On the other hand, higher energy prices can make the production of agricultural goods more expensive by raising the costs of mechanical cultivation, energy-related inputs like fertilizers and pesticides, and transportation of both inputs and outputs. Second, the growing and more prosperous world population is demanding not only more food but also more diversified agricultural products. Rapid economic growth in many emerging and developing countries has led to increases in consumption, thereby driving up food prices. Finally, the adverse effects of the global warming of the climate change, together with the flows of speculative capital into commodity markets, have also been responsible for the spikes in the food and energy prices. For example, the severe drought in 2002-2003 in Australia, one of the world's largest wheat producers, significantly cut down the global wheat production, thereby leading to rising wheat prices.

\footnotetext{
${ }^{2}$ FAO (2008)'s report “Soaring food prices: facts, perspectives, impacts and actions required”, June, 2008.

${ }^{3}$ The IGC statistics indicate that the wheat FOB price increased from US\$ 107 per ton on January 3, 2000 to US\$ 532 per ton on March 12, 2008, while the corn price rose from US\$ 90 per ton on January 3, 2000 to US\$ 241 per ton on March 12, 2008. On the other hand, the crude oil markets have also experienced an unprecedented boom and unstable period following the 1997-1998 financial crisis and the 2001 Dot com bubble burst. As an illustration, the West Texas Intermediate (WTI) crude oil spot price closed at \$20.74 per barrel in January 2002 but broke a record level of $\$ 133.93$ per barrel in June 2008.

${ }^{4}$ International Food Policy Research Institute (April 2008). Rising Food Prices: What Should Be Done?
} 
The above-mentioned facts suggest that there are significant interactions between energy and agricultural commodity markets. Not only the fluctuations in energy prices affect commodity prices, but also the rising commodity prices have various effects on energy markets as the energy demand and supply depend on agricultural production. With increasing globalization, the gradual liberalization of financial markets, the rapid development of advanced communication technologies, and the financialization of commodities markets, the markets of different goods and assets have become more and more interlinked. In this context, it is clearly important for policy-makers and global investors to understand the crossmarket relationships, and particularly between the energy and commodity markets.

The idea thus consists of gaining valuable insights into the commodity price development process, the price interaction mechanisms, the proper diversification opportunities, the portfolio optimization, and the future regulation frameworks. If, for example, the return and volatility are found to spread from one market to another, portfolio managers and policymakers would have to adjust their actions to essentially prevent contagion risks in the advent of market crashes or crises. The specific patterns of volatility in the agricultural commodity markets also render the study of return and volatility spillovers more attractive. Wright (2011) reports that agricultural commodity prices fell sharply during the summer of 2008, but recovered swiftly, and have exhibited unusually large and sustained volatility. This volatile pattern is potentially due to a number of factors including the increasing demand in developing countries, the depreciation of the US dollar, the supply shocks in the key producing regions, the irregular climate conditions, different stock market phases, recurring wars, higher transaction costs, increased market depth, and the development of the biofuel industry in the United States (Gilbert and Morgan, 2010; Baffes, 2011; Kym and Signe, 2012; Richards et al., 2012; Martine et al., 2013).

The objectives of this study are twofold. We first provide a comprehensive framework to examine the volatility transmission among the increasingly connected oil and cereal markets. The oil commodities include WTI, European Brent, gasoline and heating oil \#2, while the cereal products comprise barley, corn, sorghum and wheat. We then analyze the impacts of three types of the OPEC news announcements on the oil markets as well as on the relationship between the oil and cereal markets under consideration in order to discern if these different announcements induce asymmetric market signals for decision makers.

Several reasons motivate this study. First, over the last 10 years, the cereal markets have experienced rapid growth in liquidity and a number of investors are questioning the in- 
terest of cereal commodities as an integrative part of portfolio investments. Second, the recurring large fluctuations of cereal prices have also caused great concerns among researchers, policy makers and market participants. Policymakers in developing countries often do not have sufficient information to gauge the likely adverse effects of higher global food prices on their countries and also design appropriate policy actions (Benson et al., 2013). They therefore require better information to assess the impact of higher cereal prices on the real and financial aspects of their economies, and thereby appropriately design and implement national policies and programs to smooth out the associated risks. Finally, our empirical framework allows us to explicitly take into account the impact of the periodic OPEC announcements on the shock and volatility transmission between the energy and cereal markets, which is not always the case in related past studies (e.g., Demirer and Kutan, 2011; Schmidbauer and Rösch, 2012; and references therein).

Empirically, we use the flexible multivariate GARCH (MGARCH) specifications, namely the VAR-BEKK-GARCH and the VAR-DCC-GARCH models to explore the return and volatility interactions among eight major energy and cereal commodities. ${ }^{5}$ These models allow one to simultaneously estimate the return and volatility cross-effects across the commodities under consideration. On the other word, the multivariate GARCH approach provides further explanations of the origins, directions and transmission intensity of the shocks in at least two markets. The BEKK models capture the effects on the current conditional volatility of own innovations and lagged volatility as well as the cross market shocks and the volatility transmission of other markets. The DCC models drop the unrealistic hypothesis of timeinvariance of the conditional correlations over time.

Interestingly, the DCC models are commonly used to create and evaluate a portfolio, while the BEKK models and covariance models are employed to forecast the Value-at-Risk $(\mathrm{VaR})$ thresholds. The information revealed from these methods allows for an optimal asset allocation, construction of global hedging policies and the development of various regulatory requirements. Caporin and McAleer (2009) show many similarities and dissimilarities between the BEKK and DCC models. ${ }^{6}$ In this study, we look at the relevance role of OPEC announcements as a possible driver of the returns and volatility of the fuel and cereal group of commodities.

\footnotetext{
${ }^{5}$ The acronym BEKK refers to Baba, Engle, Kraft and Kroner, while DCC means Dynamic Conditional Correlations.

${ }^{6}$ For more details on convergence and divergence points between the BEKK and DCC models, see Caporin and McAleer (2009).
} 
Using daily data from 3 January 2000 to 29 January 2013, our main results provide evidence of significant volatility transmission among the oil and cereal markets. More interestingly, the OPEC news announcements are found to exert influence on the oil markets as well as on the oil-cereal relationships. Finally, we show that the persistence of commodity volatility decreases (increases) for the crude oil and heating (gasoline) returns. However, the results are more mixed for the cereal markets after accounting for the OPEC announcements in the multivariate GARCH models.

The rest of this article is organized as follows. Section 2 presents a brief review of the major studies in the related literature. Section 3 introduces the econometric methodology. Section 4 describes the data and some preliminary analysis. Section 5 reports and discusses the empirical results. We provide concluding remarks in Section 6.

\section{Literature review}

There is now an emerging strand of the literature that focuses on the shock transmission and volatility spillovers between the energy and agricultural commodity markets, using different datasets and various econometric methods (e.g., Chen et al., 2010; Serra, 2011; Du et al., 2011; Nazlioglu, 2011; Nazlioglu and Soytas, 2011; Ji and Fan, 2012; Hammoudeh et al., 2012; Mensi et al., 2013; Creti et al., 2013; Nazlioglu et al., 2013). This growing literature has generally demonstrated significant interactions of the return and volatility between the energy and agricultural commodity markets, but the strength of these interactions typically depends on the pairs of markets considered.

For instance, Chen et al. (2010) examine the relationships between the crude oil WTI futures price and the global grain prices for corn, soybean and wheat, and conclude that the grain price changes are significantly influenced by the changes in the price of crude oil and other grains. Nazlioglu (2011) investigates the causal relationships between the world oil and three agricultural commodity prices (corn, soybeans and wheat), and shows evidence of nonlinear feedbacks. The author also finds evidence of a persistent unidirectional nonlinear causality running from the oil prices to the corn and soybeans prices. In a related study, Nazlioglu and Soytas (2011) examine the short- and long-run interdependence between the world oil prices, lira-dollar exchange rate, and individual agricultural commodity prices (i.e., wheat, maize, cotton, soybeans, and sunflower) in Turkey. These authors find evidence of neutrality for the agricultural commodity markets in Turkey with respect to both the direct 
and indirect effects of the oil price changes. More precisely, they show that the Turkish agricultural prices do not significantly react to shocks affecting the oil prices and the exchange rates in the short-run. In addition, the long-run causality analysis indicates that the changes in the oil prices and the appreciation/depreciation of the Turkish lira are not transmitted to the agricultural commodity prices in Turkey. Sari et al. (2012) examine the roles of futures prices of crude oil, gasoline, ethanol, corn, soybeans and sugar in the energy-grain nexus, while considering the own- and cross-market impacts for the lagged grain trading volume and the open interest in the energy and grain markets. They reveal that the conventional view, which states that the impacts run from oil to gasoline to ethanol to grains in the energy-grain nexus, does not hold well in the long-run because the oil price is influenced by gasoline, soybeans and soybean oil. Moreover, gasoline is preceded by only the oil price, and ethanol is not foreshadowed by any of the prices. Equally important, there is a two-way feedback in the shortrun for all markets. The grain trading volume effect across the oil and gasoline markets is more pronounced in the short-run than in the long-run.

Vivian and Wohar (2012) examine whether there are structural breaks in the commodity spot return volatility. They first use the iterative cumulative sum of squares procedure to detect structural change and then the GARCH $(1,1)$ to model the volatility dynamics during each regime. They report very limited evidence of commodity volatility breaks during the recent financial crisis, and find that the commodity volatility persistence remains very high for many commodity returns even after structural breaks have been accounted for. Reboredo (2012) examines the dependence structure between the food and oil markets through the copula approach and find weak oil-food dependence and no extreme market dependence between the oil and food prices.

Serra (2011) uses a semi-parametric GARCH model to examine the volatility transmission between the crude oil, ethanol and sugar prices in Brazil and finds strong volatility links. Similarly, Du et al. (2011) show evidence of volatility spillovers among the crude oil, corn and wheat markets after the fall of their prices in 2006. They explain the results by the presence of tightened interdependence between the crude oil and other commodity markets, which is induced by ethanol production. Using a bivariate EGARCH model with timevarying correlations, Ji and Fan (2012) discuss the connection between the crude oil market and the non-energy commodity markets before and after the 2008 financial crisis. While considering the US dollar index as an exogenous shock, these authors find that the crude oil market has significant volatility spillover effects on non-energy commodity markets and that the influence of the US dollar index on commodity markets has weakened since the crisis. In a 
more recent study, Mensi et al. (2013) use the VAR-GARCH model to investigate the return links and volatility transmission between the S\&P 500 and the commodity price indices for energy, food, gold and beverage over the turbulent period 2000-2011. They document significant volatility transmission between the S\&P 500 index and the commodity markets. In particular, they show that past shocks and past volatility of the S\&P 500 index have strong influence on the oil and gold markets.

Similarly, Creti et al. (2013) use a DCC-GARCH model to investigate the connections between the price returns for 25 commodities covering various commodity and equity sectors including energy, precious metals, agricultural, non-ferrous metals, food, oleaginous, exotic and livestock, and stocks. These authors find that the correlations between the commodity and stock markets evolve through time and are highly volatile, particularly since the 2008 subprime mortgage crisis. Nazlioglu et al. (2013) examine volatility transmission between the oil and selected agricultural commodity prices (wheat, corn, soybeans, and sugar), but apply the newly developed causality in the variance test of Hafner and Herwartz (2006) and the impulse response functions. Their results obtained from the variance causality test show that the oil market volatility spills over to the agricultural markets- with the exception of sugar- in the post-crisis period (January 1, 2006 to March 21, 2011). However, there is no risk transmission between them in the pre-crisis period (January 1, 1986 to December 31, 2005). Gardebroek and Hernandez (2013) use the multivariate GARCH approach to examine volatility transmission between the oil, ethanol and corn prices in the United States. The empirical results support a higher correlation between the ethanol and corn markets particularly after 2006 when ethanol became the sole alternative oxygenate for gasoline. Moreover, they show significant volatility spillovers from the corn to the ethanol prices but not the converse. However, they fail to find major cross-market volatility effects running from the oil to the corn markets. Similarly, Wu and Shiping (2013) analyze the volatility spillovers in China's crude oil, corn and fuel ethanol markets and find bidirectional spillovers between the corn and fuel ethanol markets. Furthermore, no significant spillover effects from the corn and fuel ethanol markets to the crude oil market are observed.

Differently, Richards et al. (2012) focus on the asymmetric reactions of firms to positive commodity price shocks and negative commodity price shocks. Specifically, they consider the recent volatility in food commodity prices over the period 2007-2010 and investigate how commodity price shocks translate into market power in two different verticallystructured food product industries: potatoes and fluid milk. They find that both the wholesale 
and retail market power in potatoes industry decreases (increases) during periods of rising (falling) commodity prices. The price-cost margins also widen in response to negative shocks substantially greater than they narrow in response to positive shocks. As to fluid milk, the market power likewise is found to decline during periods of rising commodity prices, but does not significantly change during periods of falling commodity prices.

It is finally worth noting that the multivariate GARCH-based models have been used in a number of studies focusing on commodity markets, and their comparative performance has also been examined. Some studies have demonstrated the superiority of the VARGARCH model of Ling and McAleer (2003) over several alternatives in modeling return and volatility cross effects. For example, Hammoudeh et al. (2009) show that the VAR(1)$\operatorname{GARCH}(1,1)$ model is useful and suitable for modeling the dynamic volatility and volatility transmission for three major industrial sectors (Service, Banking and Industrial/or Insurance) in four Gulf Cooperation Council (GCC) countries. Using crude oil and stock market data, Arouri et al. (2011) provide evidence of the superiority of the VAR-GARCH model over three competing models (CCC-GARCH, DCC-GARCH and BEKK-GARCH) in terms of portfolio diversification and hedging effectiveness.

Chang et al. (2011) also compare the performance of several dynamic multivariate volatility models (CCC, VARMA-GARCH, DCC, BEKK and diagonal BEKK) by calculating the optimal portfolio weights and optimal hedge ratios for the crude oil spot and futures markets. These authors indicate that the weights of the optimal portfolio in all multivariate volatility models for the Brent oil suggest holding oil futures in larger proportions than Brent spot. For the WTI market, the DCC, BEKK and diagonal BEKK specifications suggest holding more crude oil futures than spot, but the CCC and VARMA-GARCH specifications suggest holding more crude oil spot than futures. Overall, their results indicate that the diagonal BEKK is found to be the best model for crude oil hedging effectiveness.

\section{Econometric methodology}

Since the objective of our study is to examine the return and volatility spillovers between the energy and cereal markets, the MGARCH models appear to be the most suitable approach. In particular, we rely on the use of two relatively flexible volatility models that explicitly incorporate the direct transmission of shocks and volatility across markets. This section begins with the presentation of the conditional means in the multivariate framework, and 
then introduces the two MGARCH specifications under consideration.

\subsection{VAR model for the conditional mean specification}

For the empirical analysis on return spillovers, we assume that the conditional mean of returns on the energy and cereal markets can be described by a vector autoregressive (VAR) model. In the two-variable case, a VAR (1) model can be set up as follows ${ }^{7}$

$$
\begin{aligned}
& r_{t}^{e}=\mu^{e}+a^{e} r_{t-1}^{e}+b^{e} r_{t-1}^{c}+\varepsilon_{t}^{e} \\
& r_{t}^{c}=\mu^{c}+a^{c} r_{t-1}^{c}+b^{c} r_{t-1}^{e}+\varepsilon_{t}^{c}
\end{aligned}
$$

where $r_{t}^{e}$ and $r_{t}^{c}$ are the logarithmic returns of the energy and cereal price series, respectively. The residuals, $\varepsilon_{t}^{e}$ and $\varepsilon_{t}^{c}$, are assumed to be serially uncorrelated, but the covariance $E\left(\varepsilon_{t}^{e} \varepsilon_{t}^{c}\right)$ needs not be zero. The coefficients $a^{e}$ and $a^{c}$ provide the measures of own-mean spillovers, whereas the coefficients $b^{e}$ and $b^{c}$ measure the cross-mean spillovers between the energy and cereal markets.

\subsection{MGARCH models for conditional variance}

We model the dynamics of the conditional volatility and volatility interdependence between the energy and cereal markets by using two multivariate GARCH $(1,1)$ specifications. The first specification is the full BEKK-GARCH model developed by Engle and Kroner (1995), which is suitable for accounting for not only volatility persistence of each market but also for the own- and cross-volatility spillover effects between the markets. The second specification is the DCC-GARCH model proposed by Engle (2002), which is flexible enough for modelling large variance-covariance matrices and explicitly accommodates the crossmarket comovements through time. ${ }^{8}$

We define the conditional variance-covariance matrix $\left(H_{t}\right)$ of the residuals $\left(\varepsilon_{t}^{e}\right.$ and $\left.\varepsilon_{t}^{c}\right)$ as follows

$$
\varepsilon_{t} \mid \Omega_{t-1} \sim N\left(0, H_{t}\right), \quad H_{t} \equiv\left[\begin{array}{ll}
h_{t}^{e e} & h_{t}^{e c} \\
h_{t}^{c e} & h_{t}^{c c}
\end{array}\right]
$$

where $\varepsilon_{t}$ is the $(2 \times 1)$ vector of residuals that we obtain from the VAR model and $\Omega_{t-1}$ is the

\footnotetext{
${ }^{7}$ The appropriate lag length of the VAR model is determined using the SIC information criteria. See also Table 3 for more details.

${ }^{8}$ Bauwens et al. (2006) provide a comprehensive survey of the MGARCH models.
} 
information set containing all the information available up to time $(t-1)$. Note that different specifications of $H_{t}$ will lead to different multivariate GARCH models. For instance, Engle and Kroner (1995) introduce the BEKK representation of the multivariate GARCH models by specifying the positive definite covariance matrix. Specifically, the bivariate BEKK-GARCH takes the following form

$$
H_{t}=C C^{\prime}+A \varepsilon_{t-1} \varepsilon_{t-1}^{\prime} A^{\prime}+B H_{t-1} B^{\prime}
$$

where $C$ is a $(2 \times 2)$ upper triangular matrix of constants with elements $c_{i j} ; A$ is a $(2 \times 2)$ matrix of coefficients $a_{i j}$ that capture the effects of own shocks and cross-market shock interactions; and $B$ is a $(2 \times 2)$ matrix of coefficients $b_{i j}$ that capture the own volatility persistence and the volatility interactions between markets $i$ and $j$. The estimation of the BEKKGARCH models is carried out by the quasi-maximum likelihood (QML) method, where the conditional distribution of $\varepsilon_{t}$ is assumed to follow a joint Gaussian log-likelihood function for a sample of $T$ observations and $k=2$ in bivariate model as follows 9

$$
\log L=-\frac{1}{2} \sum_{t=1}^{T}\left[k \log (2 \pi)+\ln \left|H_{t}\right|+\varepsilon_{t}^{\prime} H_{t}^{-1} \varepsilon_{t}\right] .
$$

Engle (2002) develops a MGARCH model with dynamic conditional correlations (DCC) where the positive definiteness of $H_{t}$ is guaranteed under simple conditions imposed on specific parameters. The most attractive feature of the DCC-GARCH model is that it allows for directly inferring the time-varying correlations between energy and cereal markets as well as for dealing with a relatively large number of variables in the system. In the bivariate case, the variance-covariance matrix of residuals is specified as

$$
H_{t}=D_{t} R_{t} D_{t},
$$

where $D_{t}=\operatorname{diag}\left(\sqrt{h_{t}^{e e}}, \sqrt{h_{t}^{c c}}\right)$ is the $(2 \times 2)$ diagonal matrix of the conditional standard deviations of the residuals, which are obtained from taking the square root of the conditional variance modelled by a univariate $\operatorname{GARCH}(1,1)$ process, $h_{t}=\omega+\alpha \varepsilon_{t-1}^{2}+\beta h_{t-1}$. Moreover, $R_{t}$ is a matrix of time-varying conditional correlations, which is given by

\footnotetext{
${ }^{9}$ If the conditional distribution is not normal, the quasi-maximum likelihood estimation is used to maximize the log-likelihood function. For the asymptotic properties of the ML and QML estimator, see Jeantheau (1998) and Comte and Lieberman (2003).
} 


$$
R_{t}=\left[\rho_{t}^{i j}\right]=\operatorname{diag}\left(Q_{t}\right)^{-1 / 2} Q_{t} \operatorname{diag}\left(Q_{t}\right)^{-1 / 2}
$$

The $(2 \times 2)$ symmetric positive-definite matrix $R_{t}$ depends on squared standardized residuals $\left(u_{i, t}=\varepsilon_{t}^{i} / \sqrt{h_{t}^{i i}}\right)$, their unconditional variance-covariance matrix $(\bar{Q})$, and its own lagged value according to Eq. (8).

$$
Q_{t}=\left(1-\kappa_{1}-\kappa_{2}\right) \bar{Q}+\kappa_{1} u_{t-1} u_{t-1}^{\prime}+\kappa_{2} Q_{t-1}, \text { with } \kappa_{1}, \kappa_{2}>0 \text { and } \kappa_{1}+\kappa_{2}<1
$$

Thus, we can rewrite the bivariate DCC-GARCH $(1,1)$ model as follows

$$
H_{t}=D_{t} R_{t} D_{t}=\left[\begin{array}{cc}
h_{t}^{e e} & \rho_{t}^{e c} \sqrt{h_{t}^{e e} h_{t}^{c c}} \\
\rho_{t}^{e c} \sqrt{h_{t}^{e e} h_{t}^{c c}} & h_{t}^{c c}
\end{array}\right] .
$$

The correlation coefficient between energy and cereal markets at time $t$ is given by

$$
\rho_{t}^{e c}=\frac{E_{t-1}\left[\varepsilon_{t}^{e} \varepsilon_{t}^{c}\right]}{\sqrt{E_{t-1}\left[\left(\varepsilon_{t}^{e}\right)^{2}\right]} \sqrt{E_{t-1}\left[\left(\varepsilon_{t}^{c}\right)^{2}\right]}} .
$$

The parameters of the DCC-GARCH model are estimated by using the quasimaximum likelihood (QML) method with respect to the log-likelihood function in Eq. (11) and according to a two-step estimation procedure. In the first stage, we fit the univariate GARCH(1,1) model for each of the return series and obtain the estimates of $h_{t}^{i i}$. In the second stage, the estimated parameters of the first stage are used to compute the dynamic conditional correlations.

$$
\log L=-\frac{1}{2} \sum_{t=1}^{T}\left[k \log (2 \pi)+2 \log \left|D_{t}\right|+\log \left|R_{t}\right|+\varepsilon_{t}^{\prime} R_{t}^{-1} \varepsilon_{t}\right]
$$

\section{Sample data and preliminary analysis}

We use daily closing spot price data for four oil markets including Europe Brent, West Texas Intermediate (WTI), gasoline, and heating oil \#2 as well as for four cereal markets comprising barley, corn, sorghum and wheat (in FOB Gulf). The study period runs from January 3, 2000 through January 29, 2013, which covers several episodes of wide instabilities and crises (e.g., Gulf wars, terrorist attacks, Libyan revolution, the food price surge of 20072008 , and the global financial crisis). The data for the oil prices are extracted from the Energy Information Administration (EIA), while the data for the cereal prices come from the Interna- 
tional Grains Council (IGC). We also consider the announcements of the OPEC regarding the decisions on oil production level that are taken during its official meetings. The list of official announcements was compiled from the press releases reported by the OPEC secretariat.

As the OPEC announcements may have asymmetric effects on the behavior of oil prices, we distinguish between "cut" decisions, "maintain" decisions and "hike" decisions concerning oil production. Surprisingly, a "maintain" decision may have more impact on prices and volatility than the other two decisions because it may signal that OPEC's house is in order and OPEC is in control. Over the study period, we gathered a total of 56 OPEC meetings. From the OPEC interventions, we observe 12 decisions to cut, 33 decisions to maintain, and 11 decisions to increase the current level of oil production. The OPEC decisions are the main driver of the oil price shifts and those decisions' influence on the crude oil price return volatility is generally occasional and transitory. Indeed, Bina and Vo (2007) show that the volatility impact of the OPEC production decisions is transitory and this impact is confined strictly within event windows. They add that the global oil market is the prime mover, while OPEC follows its trajectory accordingly and consistently.

Figure 1 displays the dynamics of the daily oil and cereal prices. We can see some periods of significant price fluctuations and the patterns of price development are somewhat similar for the oil types and the cereals. The red-shaded regions represent the spectacular decline in oil prices between July 1, 2008 and April 1, 2009 which occurred near the bottom of the recent global financial and food crises. During the same period, the cereal prices show a concurrent drop with the decrease in the oil prices (see the shaded zone), indicating higher correlations among both commodities during that time period. For example, the WTI (Brent) price reached \$US 145.16 (\$US 135.24) per barrel on July 14, 2008 and then dropped to \$US 104.05 (\$US 109.33). However, for the cereal prices, the wheat (corn) price attained \$US 342 (\$277) fob Gulf and the plunged to \$US 237 (\$173) in April 2009. The spikes in the prices of oil and cereal are shown between January 2007 and April 2008 (see the shaded blue region), indicating the impact of the 2007-2008 food crisis. The common trend between the oil and cereal commodity prices justifies the presence of shocks and volatility transmission between both markets, and thus warranting the use of the multivariate approach. 

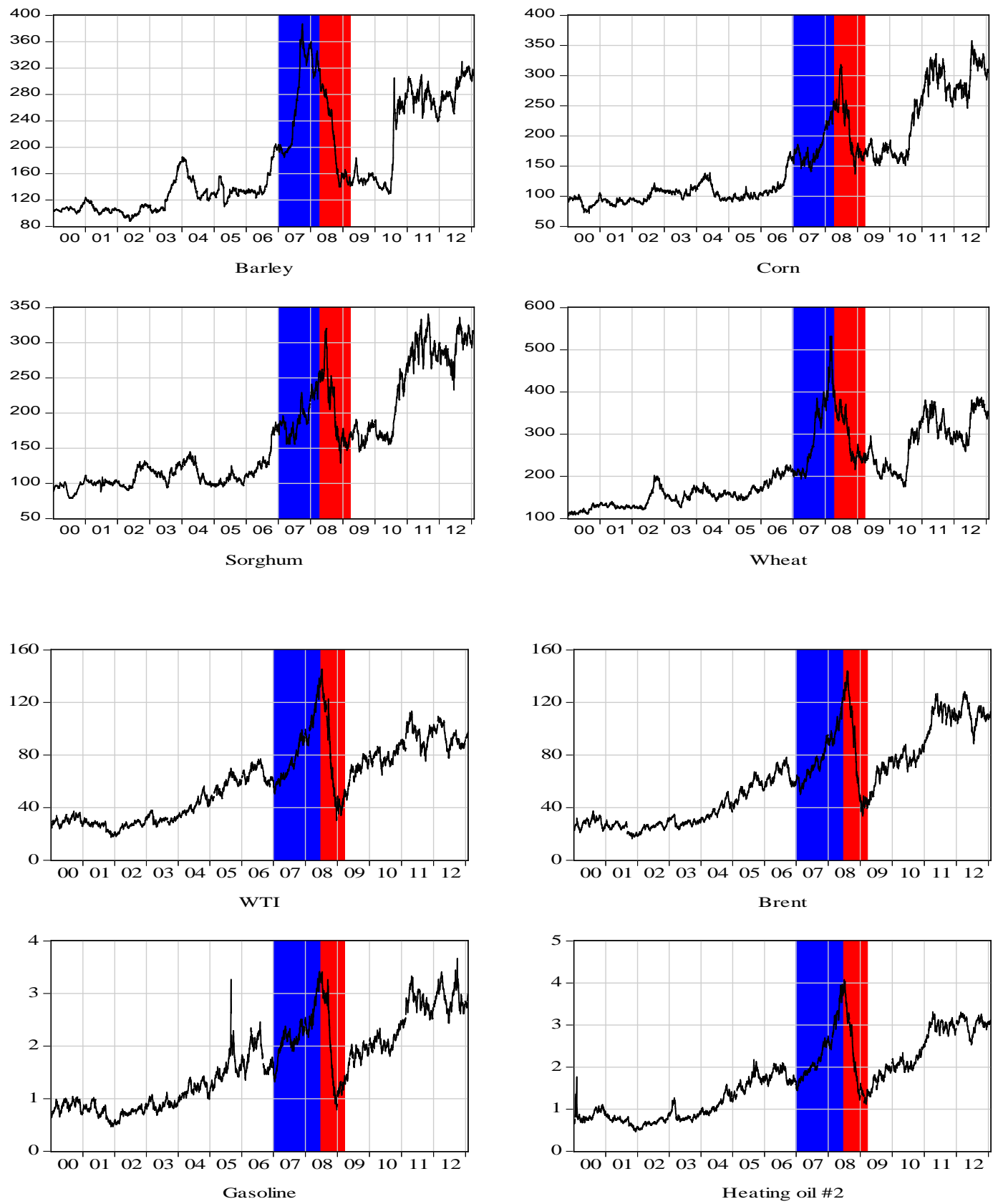

Fig. 1: Daily price dynamics of the oil and cereal markets

We calculate the continuously compounded daily returns by taking the difference in the logarithms of two consecutive prices. Table 1 provides the descriptive statistics of the daily returns and the results of statistical tests. Panel A of Table1 shows that the average daily returns range from $0.0295 \%$ (for wheat) to $0.0466 \%$ (for heating oil). The unconditional volatility as measured by the standard deviation ranges from 1.39 (barley) to 2.89 (gasoline). The skewness coefficients are negative for all return series, except the gasoline and wheat returns. 
The kurtosis coefficients are above three for all the return series. These findings indicate that the probability distributions of the oil and cereal returns are skewed and leptokurtic, which thus rejects the normality that is also confirmed by the Jarque-Bera statistics (JB). The Qstatistics show that all the return series are serially correlated, except for the wheat return. The information contained in the past returns is thus relevant for return forecasting.

The Augmented Dickey-Fuller (ADF) and the Phillips-Perron (PP) unit root tests as well as the Kwiatkowski-Phillips-Schmidt-Shin (KPSS) stationarity test are also performed. The results reported in Panel B of Table 1 indicate that all the return series are stationary at the $1 \%$ level. Finally, the Engle (1982) test for conditional heteroscedasticity shows that the ARCH effects are significantly present in all the return series, which clearly supports our decision to use the GARCH-based approach to examine the return and volatility transmission among the oil and cereal markets.

Table 1: Statistical properties of daily returns

\begin{tabular}{|c|c|c|c|c|c|c|c|c|}
\hline & WTI & Brent & Heating & Gasoline & Wheat & Corn & Sorghum & Barley \\
\hline \multicolumn{9}{|c|}{ Panel A: Basic descriptive statistics } \\
\hline Mean & 0.0378 & 0.0462 & 0.0466 & 0.0442 & 0.0295 & 0.0338 & 0.0345 & 0.0311 \\
\hline Std. dev. & 2.5415 & 2.3525 & 2.7378 & 2.8859 & 1.6353 & 1.6776 & 1.6691 & 1.3856 \\
\hline Skewness & -0.2614 & -0.2847 & -1.7501 & 0.0267 & 0.0275 & -0.0936 & -0.2440 & -0.1143 \\
\hline Kurtosis & 7.5057 & 8.4176 & 45.0681 & 7.1251 & 4.9091 & 6.0277 & 7.1426 & 30.1865 \\
\hline JB & 2794.78 & 4030.76 & 242051.40 & 2311.77 & 495.46 & 1249.97 & 2363.46 & 100402.20 \\
\hline $\mathrm{Q}(20)$ & $56.01^{+++}$ & $46.81^{+++}$ & $69.53^{+++}$ & $40.09^{+++}$ & 21.83 & $30.80^{+}$ & $44.19^{+++}$ & $82.07^{+++}$ \\
\hline \multicolumn{9}{|c|}{ Panel B: Unit root tests } \\
\hline$\overline{\mathrm{ADF}}$ & $-58.48^{+++}$ & $-56.73^{+++}$ & $-57.38^{+++}$ & $-55.14^{+++}$ & $-56.02^{+++}$ & $-54.58^{+++}$ & $-53.43^{+++}$ & $-21.66^{+++}$ \\
\hline PP & $-58.68^{+++}$ & $-56.74^{+++}$ & $-57.57^{+++}$ & $-55.11^{+++}$ & $-56.02^{+++}$ & $-54.54^{+++}$ & $-53.44^{+++}$ & $-55.57^{+++}$ \\
\hline KPSS & 0.04 & 0.03 & 0.04 & 0.02 & 0.04 & 0.04 & 0.04 & 0.06 \\
\hline \multicolumn{9}{|c|}{ Panel C: Conditional heteroscedasticity test } \\
\hline $\begin{array}{l}\text { ARCH-LM } \\
\text { tests }\end{array}$ & $189.40^{+++}$ & $24.28^{+++}$ & $172.19^{+++}$ & $155.31^{+++}$ & $71.44^{+++}$ & $89.92^{+++}$ & $49.09^{+++}$ & $12.36^{+++}$ \\
\hline
\end{tabular}

Notes: J-B and Q(20) refer to the empirical statistics of the Jarque-Bera test for normality and the Ljung-Box test for autocorrelation, respectively. ADF, PP and KPSS are the empirical statistics of the Augmented Dickey and Fuller (1979), and the Phillips and Perron (1988) unit root tests, and the Kwiatkowski et al. (1992) stationarity test, respectively. ${ }^{+++}$denotes the rejection of the null hypotheses of normality, no autocorrelation, unit root, non-stationarity, and conditional homoscedasticity at the $1 \%$ significance level.

Table 2: Unconditional correlations of sample returns.

\begin{tabular}{|c|c|c|c|c|c|c|c|c|}
\hline & WTI & Brent & Heating & Gasoline & Wheat & Corn & Sorghum & Barley \\
\hline$\overline{\text { WTI }}$ & 1.0000 & $0.5657^{+++}$ & $0.6326^{+++}$ & $0.6282^{+++}$ & $0.2080^{+++}$ & $0.2183^{+++}$ & $0.2196^{+++}$ & $0.1202^{+++}$ \\
\hline Brent & & 1.0000 & $0.4598^{+++}$ & $0.4526^{+++}$ & $0.1392^{+++}$ & $0.1555^{+++}$ & $0.1600^{+++}$ & $0.1409^{+++}$ \\
\hline Heating & & & 1.0000 & $0.5953^{+++}$ & $0.1524^{+++}$ & $0.1621^{+++}$ & $0.1621^{+++}$ & $0.0867^{+++}$ \\
\hline Gasoline & & & & 1.0000 & $0.1273^{+++}$ & $0.1298^{+++}$ & $0.1389^{+++}$ & $0.0696^{+++}$ \\
\hline Wheat & & & & & 1.0000 & $0.5524^{+++}$ & $0.5443^{+++}$ & $0.2037^{+++}$ \\
\hline Corn & & & & & & 1.0000 & $0.8301^{+++}$ & $0.1540^{+++}$ \\
\hline Sorghum & & & & & & & 1.0000 & $0.1786^{+++}$ \\
\hline Barley & & & & & & & & 1.0000 \\
\hline
\end{tabular}


Table 3: Pairwise Granger causality tests between returns of energy and cereal markets.

\begin{tabular}{lcclcc}
\hline Null hypothesis & Lags & F-value & Null hypothesis & Lags & F-value \\
\hline WTI $\neq>$ Wheat & 1 & $8.0801^{+++}$ & Wheat $\neq>$WTI & 1 & 0.1517 \\
WTI $\neq>$ Corn & 1 & $6.0549^{++}$ & Corn $\neq>$WTI & 1 & 0.0194 \\
WTI $\neq>$ Sorghum & 1 & 1.4723 & Sorghum $\neq>$ WTI & 1 & 0.0986 \\
WTI $\neq>$ Barley & 1 & $4.3617^{++}$ & Barley $\neq>$WTI & 1 & 1.2211 \\
Brent $\neq>$ Wheat & 1 & $2.9575^{+}$ & Wheat $\neq>$Brent & 1 & $17.6122^{+++}$ \\
Brent $\neq>$Corn & 1 & $3.4956^{+}$ & Corn $\neq>$Brent & 1 & $11.5765^{+++}$ \\
Brent $\neq>$Sorghum & 1 & 2.5685 & Sorghum $\neq>$ Brent & 1 & $15.1067^{+++}$ \\
Brent $\neq>$Barley & 1 & 0.6925 & Barley $\neq>$ Brent & 1 & 0.0282 \\
Heating $\neq>$ Wheat & 1 & $4.7607^{++}$ & Wheat $\neq>$Heating & 1 & $3.4943^{+}$ \\
Heating $\neq>$Corn & 1 & 1.8064 & Corn $\neq>$ Heating & 1 & 0.0927 \\
Heating $\neq>$ Sorghum & 1 & 0.5288 & Sorghum $\neq>$ Heating & 1 & 0.3590 \\
Heating $\neq>$ Barley & 1 & $5.5079^{++}$ & Barley $\neq>$Heating & 1 & 0.3664 \\
Gasoline $\neq>$ Wheat & 1 & $3.8699^{++}$ & Wheat $\neq>$Gasoline & 1 & 0.0183 \\
Gasoline $\neq>$ Corn & 1 & 0.5418 & Corn $\neq>$ Gasoline & 1 & 2.2167 \\
Gasoline $\neq>$ Sorghum & 1 & 0.0008 & Sorghum $\neq>$ Gasoline & 1 & 0.0534 \\
Gasoline $\neq>$ Barley & 1 & 2.3152 & Barley $\neq>$ Gasoline & 1 & 0.4403 \\
\hline Notes The
\end{tabular}

Notes: The symbol " $\neq>$ " means "does not Granger-cause." To select the order of lags for Granger causality test, the Schwarz information criterion (SIC), also known as the Bayesian information criterion (BIC), is used. ${ }^{++},+$and $^{+}$indicate a rejection of the null hypothesis at the $1 \%, 5 \%$ and $10 \%$ significance levels, respectively. The numbers are the values for the F-statistic.

Table 2 presents the correlation matrix for sample returns. We find significant and positive correlations for all cases. The highest correlation is observed for the corn-sorghum market pair, while the lowest correlation is for the barley-heating oil market pair.

Before studying the volatility spillovers across the oil and cereal markets, we carry out the conventional Granger causality test to obtain information of how these markets are linked to each other. The results in Table 3 show evidence of various causal relationships. First, there is a unidirectional causality running from the WTI market to three cereal markets (wheat, corn and barley), supporting the spillover from the WTI oil prices to the food and animal feed prices. The causality is bidirectional from the Brent market to the wheat and corn food markets, but only unidirectional from the sorghum market to the Brent market. Interestingly, the Granger causality among the heating oil, gasoline and cereal markets is less pronounced than between the crude oil and cereal markets, probably because gasoline and heating oil are not used in fertilizers and pesticides. However, we still find a bidirectional causality between the heating oil and the wheat markets, and a unidirectional causality running from the heating oil market to barley market, as well as from the gasoline market to the wheat market. Overall, these findings, albeit dependent on the exact specification of the linear Granger causality tests, suggest the presence of substantial causal feedbacks between the oil and cereal markets. The predominant causality between the WTI and Brent oil markets can be explained by the global nature of these markets. 


\section{Empirical results}

\subsection{Return and volatility spillovers between crude oil and cereal markets}

Table 4 shows the estimates of the VAR-BEKK-GARCH models without and with the three types of the OPEC news announcements for the WTI markets. Taking a close look at the mean equations when the dummy variables for the OPEC production decisions are not accounted for, both the oil and cereal current returns (with the exception of the wheat return) depend on their own past returns $\left(a^{e}, a^{c}\right)$. This finding shows some evidence of short-term predictability in commodity price changes through time. We also find a bidirectional mean spillover $\left(b^{e}, b^{c}\right)$ across the WTI and wheat markets. The one-period lagged WTI returns influence the current corn returns, and also the past WTI returns affect the sorghum returns.

As to the conditional variance equations, the current conditional volatility of the energy and cereal markets is determined by their both own past shocks $\left(\mathrm{a}_{11}\right.$ and $\left.\mathrm{a}_{22}\right)$ and the conditional past volatility $\left(b_{11}\right.$ and $\left.b_{22}\right)$. Furthermore, a bidirectional cross-market shock effects ( $\left.a_{12}, a_{21}\right)$ across the WTI and barley markets is found, and the past WTI volatility $\left(b_{12}\right)$ affects the corn conditional volatility, likely due to their connection with the extraction of ethanol. By contrast, the past volatility of wheat and barley $\left(b_{21}\right)$ influences the WTI conditional volatility. When the OPEC news announcements are introduced as a binary variable, both the cut and increase production decisions affect the conditional volatility of the WTI crude oil markets. The presence of OPEC cut/maintain/increase decisions decreases the short-run persistence (ARCH coefficients). There is also only significant unidirectional spillover from the wheat to the WTI markets.

For comparison purposes, we estimate the VAR-DCC-GARCH model for the WTI and cereal markets and report the results in Table 5. The estimates of the DCC parameters $\left(\mathrm{k}_{1}\right.$ and $\mathrm{k}_{2}$ ) are statistically significant in all cases, leading to the rejection of the assumption of CCC (constant conditional correlations) for all news to returns. The short-run persistence of the shocks on the DCC is the highest for wheat at 0.018 ( 0.019 when we consider the dummy variables), while the largest long-run persistence of shocks to the DCC is 0.998 for barley. The cut decisions affect significantly all markets, while the increase decisions affect the energy and corn markets. The maintain decisions have a significant effect on both the sorghum and barley cereal markets. 
Table 4: Estimation results of the VAR-BEKK-GARCH model without and with OPEC news announcements (WTI)

\begin{tabular}{|c|c|c|c|c|c|c|c|c|}
\hline \multirow[b]{2}{*}{ Coef. } & \multicolumn{2}{|c|}{ WTI - Wheat } & \multicolumn{2}{|c|}{ WTI -Corn } & \multicolumn{2}{|c|}{ WTI - Sorghum } & \multicolumn{2}{|c|}{ WTI - Barley } \\
\hline & $\begin{array}{c}\text { without } \\
\text { OPEC news }\end{array}$ & $\begin{array}{c}\text { with OPEC } \\
\text { news }\end{array}$ & $\begin{array}{c}\text { without } \\
\text { OPEC news }\end{array}$ & $\begin{array}{c}\text { with OPEC } \\
\text { news }\end{array}$ & $\begin{array}{c}\text { without } \\
\text { OPEC news }\end{array}$ & $\begin{array}{c}\text { with OPEC } \\
\text { news }\end{array}$ & $\begin{array}{c}\text { without } \\
\text { OPEC news }\end{array}$ & $\begin{array}{c}\text { with OPEC } \\
\text { news }\end{array}$ \\
\hline \multicolumn{9}{|c|}{ Panel A: Conditional mean } \\
\hline \multirow{2}{*}{$\mu^{e}$} & 0.089 & 0.083 & 0.087 & 0.076 & 0.086 & 0.080 & 0.102 & 0.093 \\
\hline & $(0.036)^{* *}$ & $(0.038)^{* *}$ & $(0.036) * *$ & $(0.037)^{* *}$ & $(0.036) * *$ & $(0.039)^{* *}$ & $(0.037)^{* * *}$ & $(0.039) * *$ \\
\hline \multirow{2}{*}{$a^{e}$} & -0.038 & -0.040 & -0.036 & -0.038 & -0.031 & -0.034 & -0.035 & -0.037 \\
\hline & $(0.017)^{* *}$ & $(0.013)^{* * *}$ & $(0.017)^{* *}$ & $(0.016)^{* *}$ & $(0.016)^{*}$ & $(0.018)^{* *}$ & $(0.016)^{* *}$ & $(0.018)^{* *}$ \\
\hline \multirow{2}{*}{$b^{e}$} & 0.044 & 0.048 & 0.009 & 0.007 & 0.045 & 0.043 & -0.023 & -0.021 \\
\hline & $(0.024)^{*}$ & $(0.023)^{*}$ & $(0.022)$ & $(0.022)$ & $(0.024)^{*}$ & $(0.024)^{*}$ & $(0.026)$ & $(0.028)$ \\
\hline \multirow[t]{2}{*}{$\mathrm{cut}^{e}$} & & -0.540 & & -0.425 & & -0.485 & & -0.529 \\
\hline & & $(0.825)$ & & $(0.705)$ & & $(0.751)$ & & $(0.790)$ \\
\hline \multirow{2}{*}{ maintain $^{e}$} & & 0.107 & & 0.031 & & 0.069 & & 0.167 \\
\hline & & $(0.396)$ & & $(0.419)$ & & $(0.362)$ & & $(0.390)$ \\
\hline \multirow{2}{*}{ increase $^{e}$} & & 0.684 & & 0.544 & & 0.412 & & 0.467 \\
\hline & & $(0.981)$ & & (0.899) & & $(0.910)$ & & $(0.921)$ \\
\hline \multirow{2}{*}{$\mu^{c}$} & 0.027 & 0.026 & 0.011 & 0.008 & 0.043 & 0.035 & 0.047 & 0.049 \\
\hline & $(0.024)$ & $(0.025)$ & $(0.023)$ & $(0.028)$ & $(0.022)^{* *}$ & $(0.023)$ & $(0.015)^{* * *}$ & $(0.021) * *$ \\
\hline \multirow{2}{*}{$a^{c}$} & 0.022 & 0.024 & 0.042 & 0.041 & 0.127 & 0.136 & 0.096 & 0.095 \\
\hline & $(0.017)$ & (0.019) & $(0.017)^{* *}$ & $(0.016) * *$ & $(0.018) * * *$ & $(0.021)^{* * *}$ & $(0.023) * * *$ & $(0.021)^{* * *}$ \\
\hline$b^{c}$ & -0.023 & -0.024 & -0.031 & -0.032 & -0.015 & -0.015 & -0.002 & -0.004 \\
\hline 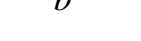 & $(0.010)^{* *}$ & $(0.010)^{* *}$ & $(0.011)^{* * *}$ & $(0.011)^{* * *}$ & (0.009) & $(0.009)^{*}$ & $(0.007)$ & (0.008) \\
\hline cut $^{c}$ & & 0.143 & & 0.376 & & 0.024 & & -0.108 \\
\hline & & $(0.301)$ & & $(0.430)$ & & $(0.291)$ & & (0.239) \\
\hline maintain $^{c}$ & & -0.057 & & 0.182 & & 0.363 & & 0.304 \\
\hline & & $(0.25$ & & $(0.254)$ & & $(0.300)$ & & (0.219) \\
\hline increase $^{c}$ & & 0.059 & & -0.751 & & -0.445 & & -0.580 \\
\hline & & $(0.419)$ & & $\left(0.4^{\top}\right.$ & & $(0.309)$ & & $(0.347)^{*}$ \\
\hline Panel B: $C$ & nditional vario & ance & & & & & & \\
\hline$c_{11}$ & 0.346 & 0.302 & 0.377 & 0.290 & 0.318 & 0.287 & 0.302 & 0.285 \\
\hline & $(0.032) * * *$ & $(0.044)^{* * *}$ & $(0.033)^{* * *}$ & $(0.065)^{* * *}$ & $(0.030)^{* * *}$ & $(0.046)^{* * *}$ & $(0.040)^{* * *}$ & $(0.045)^{* * *}$ \\
\hline$c_{12}$ & -0.029 & -0.063 & -0.066 & -0.092 & -0.048 & -0.054 & 0.204 & 0.222 \\
\hline 12 & $(0.028)$ & $(0.031)^{* *}$ & $(0.037)^{*}$ & $(0.054) *$ & $(0.031)$ & $(0.029)^{*}$ & $(0.072)^{* * *}$ & $(0.095) * *$ \\
\hline$c_{2 \vartheta}$ & -0.095 & -0.067 & 0.209 & 0.234 & 0.110 & 0.023 & -0.578 & 0.561 \\
\hline & $(0.017)^{* * *}$ & $(0.040)^{*}$ & $(0.020) * * *$ & $(0.065)^{* * *}$ & $(0.015)^{* * *}$ & (0.066) & $(0.027) * * *$ & $(0.044)^{* * *}$ \\
\hline$a_{11}$ & 0.243 & 0.222 & 0.251 & 0.208 & 0.218 & 0.198 & 0.220 & 0.201 \\
\hline$v_{11}$ & $(0.010)^{* * *}$ & $(0.022) * * *$ & $(0.011)^{* * *}$ & $(0.034) * * *$ & $(0.009)^{* * *}$ & $(0.023)^{* * *}$ & $(0.010) * * *$ & $(0.018)^{* * *}$ \\
\hline$a_{12}$ & 0.007 & 0.007 & -0.010 & -0.001 & 0.000 & 0.000 & -0.017 & -0.015 \\
\hline$u_{12}$ & (0.008) & $(0.007)$ & $(0.008)$ & $(0.010)$ & $(0.007)$ & $(0.007)$ & $(0.009)^{*}$ & $(0.011)$ \\
\hline$a_{21}$ & -0.020 & -0.020 & -0.013 & 0.002 & 0.014 & 0.009 & 0.119 & 0.112 \\
\hline$u_{21}$ & (0.019) & $(0.022)$ & $(0.023)$ & $(0.024)$ & $(0.020)$ & $(0.021)$ & $(0.030) * * *$ & $(0.033)^{* * * *}$ \\
\hline$a_{22}$ & 0.173 & 0.174 & 0.217 & 0.244 & 0.259 & 0.216 & 0.555 & 0.582 \\
\hline$u_{22}$ & $(0.010)^{* * *}$ & $(0.016) * * *$ & $(0.013)^{* * *}$ & $(0.044) * * *$ & $(0.010)^{* * *}$ & $(0.013)^{* * *}$ & $(0.012) * * *$ & $(0.038)^{* * *}$ \\
\hline$b_{11}$ & 0.959 & 0.963 & 0.955 & 0.967 & 0.967 & 0.969 & 0.968 & 0.970 \\
\hline & $(0.004)^{* * *}$ & $(0.007) * * *$ & $(0.005)^{* * *}$ & $(0.010)^{* * *}$ & $(0.003)^{* * *}$ & $(0.007)^{* * *}$ & $(0.004)^{* * *}$ & $(0.005)^{* * *}$ \\
\hline$b_{12}$ & -0.001 & 0.000 & 0.006 & 0.004 & 0.002 & 0.001 & 0.005 & 0.003 \\
\hline & $(0.002)$ & $(0.002)$ & $(0.003)^{* *}$ & $(0.003)$ & $(0.002)$ & $(0.002)$ & $(0.005)$ & (0.006) \\
\hline$b_{21}$ & 0.010 & 0.011 & 0.011 & 0.008 & 0.003 & 0.004 & -0.071 & -0.062 \\
\hline & $(0.005)^{*}$ & $(0.005)^{* *}$ & $(0.007)$ & $(0.008)$ & $(0.005)$ & $(0.005)$ & $(0.017)^{* * *}$ & $(0.021)^{* * *}$ \\
\hline$b_{22}$ & 0.983 & 0.982 & 0.966 & 0.958 & 0.966 & 0.974 & 0.751 & 0.743 \\
\hline & $(0.002)^{* * *}$ & $(0.004)^{* * *}$ & $(0.004)^{* * *}$ & $(0.016)^{* * *}$ & $(0.002)^{* * *}$ & $(0.003)^{* * *}$ & $(0.010)^{* * *}$ & $(0.027)^{* * *}$ \\
\hline cut $_{11}$ & & 1.592 & & 1.483 & & 1.638 & & 1.352 \\
\hline & & $(0.364) * * *$ & & $(0.410)^{* * *}$ & & $(0.358) * * *$ & & $(0.335)^{* * *}$ \\
\hline cut $_{12}$ & & 0.140 & & 0.069 & & 0.023 & & -0.335 \\
\hline & & $(0.152)$ & & $(0.205)$ & & $(0.132)$ & & $(0.230)$ \\
\hline cut $_{22}$ & & 0.067 & & -0.234 & & -0.023 & & -0.561 \\
\hline & & $(0.195)$ & & $(0.271)$ & & $(0.163)$ & & $(0.291)^{*}$ \\
\hline maintain $_{11}$ & & -0.972 & & -1.043 & & -0.923 & & -1.058 \\
\hline & & $(0.353)^{* * *}$ & & $(0.303)^{* * *}$ & & $(0.334)^{* * *}$ & & $(0.305)^{* * *}$ \\
\hline maintain $_{12}$ & & -0.225 & & -0.249 & & -0.362 & & -0.461 \\
\hline & & $(0.302)$ & & $(0.272)$ & & $(0.388)$ & & $(0.466)$ \\
\hline maintain $_{22}$ & & 0.470 & & -0.234 & & 1.048 & & 0.327 \\
\hline & & $(0.285)$ & & $(0.416)$ & & $(0.181)^{* *}$ & & $(0.191)^{*}$ \\
\hline
\end{tabular}




\begin{tabular}{|c|c|c|c|c|c|c|c|c|}
\hline increase $_{11}$ & & $\begin{array}{r}2.115 \\
(0.313)^{* * *}\end{array}$ & & $\begin{array}{r}2.053 \\
(0.308)^{* * *}\end{array}$ & & $\begin{array}{r}2.046 \\
(0.290) * * *\end{array}$ & & $\begin{array}{r}1.931 \\
(0.314)^{* * *}\end{array}$ \\
\hline increase $_{12}$ & & 0.080 & & 0.197 & & 0.056 & & -0.296 \\
\hline & & $(0.183)$ & & $(0.217)$ & & $(0.123)$ & & $(0.440)$ \\
\hline \multirow{2}{*}{\multicolumn{2}{|c|}{ increase $_{22}$}} & 0.067 & & -0.234 & & -0.023 & & 0.188 \\
\hline & & $(0.968)$ & & $(0.441)$ & & $(0.188)$ & & $(0.245)$ \\
\hline \multicolumn{9}{|c|}{ Panel C: Diagnostic test } \\
\hline $\log L$ & -13251.011 & -13229.214 & -13403.195 & -13381.644 & -13224.498 & -13173.933 & -12725.520 & -12702.176 \\
\hline$H Q(20)$ & $\begin{array}{r}77.100 \\
{[0.507]}\end{array}$ & $\begin{array}{r}80.125 \\
{[0.412]}\end{array}$ & $\begin{array}{r}80.088 \\
{[0.413]}\end{array}$ & $\begin{array}{r}78.679 \\
{[0.457]}\end{array}$ & $\begin{array}{r}75.745 \\
{[0.551]}\end{array}$ & $\begin{array}{r}76.878 \\
{[0.514]}\end{array}$ & $\begin{array}{r}98.085 \\
{[0.061]^{*}}\end{array}$ & $\begin{array}{r}97.671 \\
{[0.065]^{*}}\end{array}$ \\
\hline$H Q_{s}(20)$ & $\begin{array}{r}108.461 \\
{[0.012]^{* *}}\end{array}$ & $\begin{array}{r}118.104 \\
{[0.002] * * *}\end{array}$ & $\begin{array}{l}80.111 \\
{[0.412]}\end{array}$ & $\begin{array}{l}85.084 \\
{[0.272]}\end{array}$ & $\begin{array}{r}66.393 \\
{[0.822]}\end{array}$ & $\begin{array}{c}87.502 \\
{[0.216]}\end{array}$ & $\begin{array}{r}264.175 \\
{[0.000]^{* * *}}\end{array}$ & $\begin{array}{r}119.808 \\
{[0.002] * * *}\end{array}$ \\
\hline
\end{tabular}

Notes: In every pair, superscripts $e$ and $c$ represent the energy market and the cereal market, respectively. $H Q(20)$ and $H Q_{s}(20)$ are Hosking's multivariate portmanteau $Q$-statistics on the standardized residuals and the standardized squared residuals, respectively. $* * *$ and $* * *$ indicate the rejection of the $t$-test at the $10 \%, 5 \%$ and $1 \%$ significance levels, respectively. The standard errors (S.E.) are reported in the parentheses, while the P-values are reported in the brackets.

Table 5: Estimation results of the VAR-DCC-GARCH model without and with OPEC news announcements (WTI)

\begin{tabular}{|c|c|c|c|c|c|c|c|c|}
\hline \multirow[b]{2}{*}{ Coef. } & \multicolumn{2}{|c|}{ WTI - Wheat } & \multicolumn{2}{|c|}{ WTI - Corn } & \multicolumn{2}{|c|}{ WTI - Sorghum } & \multicolumn{2}{|c|}{ WTI - Barley } \\
\hline & $\begin{array}{c}\text { without } \\
\text { OPEC news }\end{array}$ & $\begin{array}{c}\text { with OPEC } \\
\text { news }\end{array}$ & $\begin{array}{c}\text { without } \\
\text { OPEC news }\end{array}$ & $\begin{array}{c}\text { with OPEC } \\
\text { news }\end{array}$ & $\begin{array}{c}\text { without } \\
\text { OPEC news }\end{array}$ & $\begin{array}{c}\text { with OPEC } \\
\text { news }\end{array}$ & $\begin{array}{c}\text { without } \\
\text { OPEC news }\end{array}$ & $\begin{array}{c}\text { with OPEC } \\
\text { news }\end{array}$ \\
\hline \multicolumn{9}{|c|}{ Panel A: Conditional mean } \\
\hline \multirow{2}{*}{$\mu^{e}$} & 0.089 & 0.087 & 0.083 & 0.083 & 0.092 & 0.075 & 0.092 & 0.092 \\
\hline & $(0.039)^{* *}$ & $(0.039) * *$ & $(0.039$ & $(0.036)^{* *}$ & & $(0.040)^{*}$ & $.038)^{* *}$ & $(0.036)^{*}$ \\
\hline \multirow{2}{*}{$a^{e}$} & -0.036 & -0.039 & -0.033 & -0.035 & -0.030 & -0.036 & -0.043 & -0.045 \\
\hline & $(0.020)^{*}$ & $(0.019) * *$ & $(0.019)^{*}$ & $(0.017)^{* *}$ & $(0.019)$ & $(0.018) * *$ & $(0.019) * *$ & $(0.017)^{* * *}$ \\
\hline \multirow[t]{2}{*}{$b^{e}$} & 0.040 & 0.044 & 0.004 & 0.004 & 0.038 & 0.045 & -0.009 & -0.009 \\
\hline & $(0.024)^{*}$ & $(0.024)^{*}$ & $(0.024)$ & $(0.0$ & $(0.025)$ & $(0.026) *$ & & $(0.025)$ \\
\hline \multirow[t]{2}{*}{ cut $^{e}$} & & -0.406 & & -0.222 & & -0.298 & & -0.130 \\
\hline & & $(0.783)$ & & $(0.659)$ & & $(0.744)$ & & $(0.617)$ \\
\hline \multirow{2}{*}{ maintain $^{e}$} & & 0.159 & & 0.096 & & 0.109 & & 0.216 \\
\hline & & $(0.385)$ & & $(0.441)$ & & $(0.383)$ & & $(0.434)$ \\
\hline \multirow[t]{2}{*}{ increase $^{e}$} & & 0.517 & & 0.455 & & 0.562 & & 0.460 \\
\hline & & (1.087) & & $(1.6$ & & $(0.875)$ & & $(1.715)$ \\
\hline \multirow{2}{*}{$\mu^{c}$} & 0.027 & 0. & 0.008 & 0. & 0.053 & 0.033 & 0.036 & 0.041 \\
\hline & $(0.0$ & $(0.0$ & $(0.0$ & & $(0.023) * *$ & $.000) * * *$ & $(0.02$ & $(0.013) * * *$ \\
\hline \multirow{2}{*}{$a^{c}$} & 0.022 & 0 . & 0.041 & & 0.135 & 0.075 & 0.099 & 0.105 \\
\hline & $(0.02$ & $(0$. & $(0.019)$ & $(0.01$ & $(0.022)^{3}$ & $(0.001)^{* * *}$ & $.023)^{* * *}$ & $(0.023)^{* * *}$ \\
\hline \multirow[t]{2}{*}{$b^{c}$} & -0.025 & -0.025 & -0.033 & -0.034 & -0.015 & -0.017 & -0. & -0.015 \\
\hline & $(0.010)^{* *}$ & $(0.010)^{* *}$ & $(0.011)^{* * *}$ & $.011)^{* * *}$ & $(0.009)^{*}$ & $(0.010)^{*}$ & $(0.008)$ & $(0.006)^{* *}$ \\
\hline \multirow[t]{2}{*}{$c u t^{c}$} & & 0.066 & & 0.287 & & 0.092 & & -0.101 \\
\hline & & $(0.270)$ & & $(0.4$ & & $(0.112)$ & & $(0.046) * *$ \\
\hline \multirow[t]{2}{*}{ maintain $^{c}$} & & -0.026 & & 0.185 & & 0.341 & & 0.287 \\
\hline & & $(0.23$ & & $\left(0.2^{\prime}\right.$ & & $(0.2$ & & $(0.307)$ \\
\hline \multirow[t]{2}{*}{ increase $^{c}$} & & 0.007 & & -0.759 & & -0.573 & & -0.548 \\
\hline & & $(0.3$ & & $(0.41)$ & & $042)$ & & $(0.6$ \\
\hline \multicolumn{9}{|c|}{ Panel B: Conditional variance } \\
\hline \multirow[t]{2}{*}{$\omega^{e}$} & 0.141 & 0.122 & 0.146 & 0.126 & 0.134 & 0.087 & 0.138 & 0.121 \\
\hline & $(0.044)^{* * *}$ & $.039) * * *$ & $(0.049)^{* * *}$ & $(0.023)^{* * *}$ & $(0.041)^{* * *}$ & $(0.030)^{* * *}$ & $(0.042) * * *$ & $(0.024)^{* * *}$ \\
\hline \multirow[t]{2}{*}{$\omega^{c}$} & 0.014 & 0.019 & 0.085 & 0.091 & 0.011 & 0.264 & 0.379 & 0.441 \\
\hline & $(0.005)^{* * *}$ & $(0.006) * * *$ & $(0.025) * * *$ & $(0.011)^{* * * *}$ & $(0.004)^{* * *}$ & $(0.000)^{* * *}$ & $(0.045) * * *$ & $(0.021)^{* * *}$ \\
\hline \multirow[t]{2}{*}{$\alpha^{e}$} & 0.066 & 0.062 & 0.070 & 0.066 & 0.068 & 0.047 & 0.069 & 0.066 \\
\hline & $(0.012) * * *$ & $(0.013) * * *$ & $(0.013)^{* * *}$ & $(0.006) * * *$ & $(0.011)^{* * *}$ & $(0.011)^{* * *}$ & $(0.012)^{* * *}$ & $(0.006)^{* * *}$ \\
\hline \multirow[t]{2}{*}{$\alpha^{c}$} & 0.042 & 0.040 & 0.085 & 0.080 & 0.080 & 0.112 & 0.362 & 0.488 \\
\hline & $(0.007)^{* * *}$ & $(0.007) * * *$ & $(0.017) * * *$ & $(0.008) * * *$ & $(0.009)^{* * *}$ & $(0.005)^{* * *}$ & $(0.044) * * *$ & $(0.018)^{* * *}$ \\
\hline$\beta^{e}$ & 0.911 & 0.912 & 0.906 & 0.908 & 0.911 & 0.932 & 0.908 & 0.909 \\
\hline & $(0.017)^{* * *}$ & $(0.018) * * *$ & $(0.020)^{* * *}$ & $(0.009)^{* * *}$ & $(0.016)^{* * *}$ & $(0.014)^{* * *}$ & $(0.017)^{* * *}$ & $(0.009)^{* * *}$ \\
\hline$\beta^{c}$ & 0.954 & 0.954 & 0.887 & 0.892 & 0.924 & 0.818 & 0.532 & 0.453 \\
\hline & $(0.008) * * *$ & $(0.008) * * *$ & $(0.023) * * *$ & $(0.009)^{* * *}$ & $(0.007)^{* * *}$ & $(0.001)^{* * *}$ & $(0.042)^{* * *}$ & $(0.015)^{* * *}$ \\
\hline$c u t^{e}$ & & 2.592 & & 2.381 & & 3.337 & & 2.690 \\
\hline & & $(1.385)^{*}$ & & $(1.325)^{*}$ & & $(1.161)^{* * *}$ & & $(1.284)^{* *}$ \\
\hline$c u t^{c}$ & & -0.476 & & -0.938 & & -1.368 & & -0.817 \\
\hline
\end{tabular}




\begin{tabular}{|c|c|c|c|c|c|c|c|c|}
\hline & & $(0.142)^{* * *}$ & & $(0.189) * * *$ & & $(0.008)^{* * *}$ & & $(0.170)^{* * *}$ \\
\hline \multirow{2}{*}{\multicolumn{2}{|c|}{ maintain $^{e}$}} & 0.381 & & 0.376 & & 0.758 & & 0.483 \\
\hline & & $(0.495)$ & & $(0.445)$ & & $(0.497)$ & & $(0.465)$ \\
\hline \multirow{2}{*}{\multicolumn{2}{|c|}{ maintain $^{c}$}} & 0.087 & & -0.241 & & -0.514 & & 0.574 \\
\hline & & $(0.164)$ & & $(0.206)$ & & $(0.228)^{* *}$ & & $(0.228)^{* *}$ \\
\hline \multicolumn{2}{|l|}{ increase $^{e}$} & 5.785 & & 5.614 & & 6.070 & & 5.821 \\
\hline & & $(1.690)^{* * *}$ & & $(0.895)^{* * *}$ & & $(0.673)^{* * *}$ & & $(0.949)^{* * *}$ \\
\hline \multicolumn{2}{|l|}{ increase $^{c}$} & $\begin{array}{r}-0.177 \\
(0.184)\end{array}$ & & $\begin{array}{r}-0.404 \\
(0.313)\end{array}$ & & $\begin{array}{r}-1.591 \\
(0.002)^{* * * *}\end{array}$ & & $\begin{array}{r}0.324 \\
(0.577) \\
\end{array}$ \\
\hline \multicolumn{9}{|c|}{ Panel C: Correlation } \\
\hline$\kappa_{1}$ & $\begin{array}{r}0.018 \\
(0.007)^{* *}\end{array}$ & $\begin{array}{r}0.019 \\
(0.007)^{* * *}\end{array}$ & $\begin{array}{r}0.010 \\
(0.004)^{* *}\end{array}$ & $\begin{array}{r}0.011 \\
(0.004)^{* * *}\end{array}$ & $\begin{array}{r}0.012 \\
(0.004)^{* * *}\end{array}$ & $\begin{array}{r}0.011 \\
(0.004)^{* * * *}\end{array}$ & $\begin{array}{r}0.010 \\
(0.004)^{* * *}\end{array}$ & $\begin{array}{r}0.010 \\
(0.004)^{* * *}\end{array}$ \\
\hline$\kappa_{2}$ & $\begin{array}{r}0.974 \\
(0.011)^{* * *} \\
\end{array}$ & $\begin{array}{r}0.971 \\
(0.012)^{* * *} \\
\end{array}$ & $\begin{array}{r}0.985 \\
(0.007)^{* * *} \\
\end{array}$ & $\begin{array}{r}0.984 \\
(0.006)^{* * *} \\
\end{array}$ & $\begin{array}{r}0.984 \\
(0.004)^{* * *} \\
\end{array}$ & $\begin{array}{r}0.985 \\
(0.006)^{* * *} \\
\end{array}$ & $\begin{array}{r}0.988 \\
(0.005)^{* * * *} \\
\end{array}$ & $\begin{array}{r}0.988 \\
(0.005)^{* * *} \\
\end{array}$ \\
\hline \multicolumn{9}{|c|}{ Panel D: Diagnostic test } \\
\hline $\log L$ & -13246.339 & -13225.645 & -13389.332 & -13368.339 & -13207.135 & -13278.542 & -12708.557 & -12686.898 \\
\hline$H Q(20)$ & $\begin{array}{r}76.715 \\
{[0.519]}\end{array}$ & $\begin{array}{r}78.980 \\
{[0.447]}\end{array}$ & $\begin{array}{r}80.510 \\
{[0.400]}\end{array}$ & $\begin{array}{c}78.573 \\
{[0.461]}\end{array}$ & $\begin{array}{c}75.724 \\
{[0.551]}\end{array}$ & $\begin{array}{r}77.297 \\
{[0.501]}\end{array}$ & $\begin{array}{r}102.885 \\
{[0.031]^{* *}}\end{array}$ & $\begin{array}{r}105.076 \\
{[0.022]^{* *}}\end{array}$ \\
\hline$H Q_{s}(20)$ & $\begin{array}{r}98.153 \\
{[0.061]^{*}}\end{array}$ & $\begin{array}{r}110.745 \\
{[0.009]^{* * *}}\end{array}$ & $\begin{array}{r}75.496 \\
{[0.559]}\end{array}$ & $\begin{array}{r}77.800 \\
{[0.485]}\end{array}$ & $\begin{array}{r}58.063 \\
{[0.955]}\end{array}$ & $\begin{array}{r}110.177 \\
{[0.010]^{* * *}}\end{array}$ & $\begin{array}{r}303.786 \\
{[0.000]^{* * *}}\end{array}$ & $\begin{array}{r}119.831 \\
{[0.002]^{* * *}}\end{array}$ \\
\hline
\end{tabular}

Notes: See notes of Table 4 .

Figures 2-3 illustrate the time-varying conditional correlations obtained from the BEKK-GARCH and DCC-GARCH models. They show significant fluctuations in the conditional correlations, especially since the 2007-2008 U.S. subprime mortgage financial crisis. ${ }^{10}$ In particular, when using the BEKK-GARCH, the conditional correlations between the oil and cereal markets evolve over time and experienced phases of decreases and increases. The highest peaks correspond to the 2007-2008 world food crisis and the 2008-2009 global financial crisis periods.

When the DCC-GARCH model is used, the DCC estimates are positive for each market pair almost over time and increase in recent years, but the magnitude of the DCC fluctuations is smaller than the dynamic correlations from the BEKK-GARCH model. It can also be seen that the level of market linkages has not changed significantly across time when we consider the OPEC news announcements. However, such decisions increase the risk and the information transmission between the oil and cereal markets.

These results lead us to conclude that the cut decisions have a fairly higher impact on the oil price instability than the maintain decisions particularly for the revenues of the oilexporting countries. They also confirm the results reached by previous studies including, for example, Wirl and Kujundzic (2004), and Schmidbauer and Rösch (2012).

${ }^{10}$ Other figures are available from the corresponding author upon request. 
Fig. 2: Conditional correlations between the WTI and cereal markets (the VAR-BEKK-GARCH model)

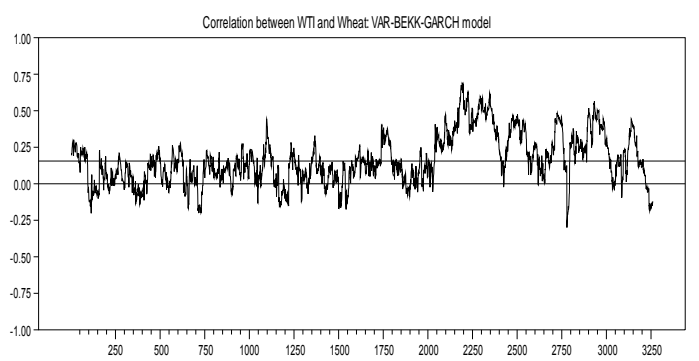

Correlation between WTI and Maize: VAR-BEKK-GARCH model
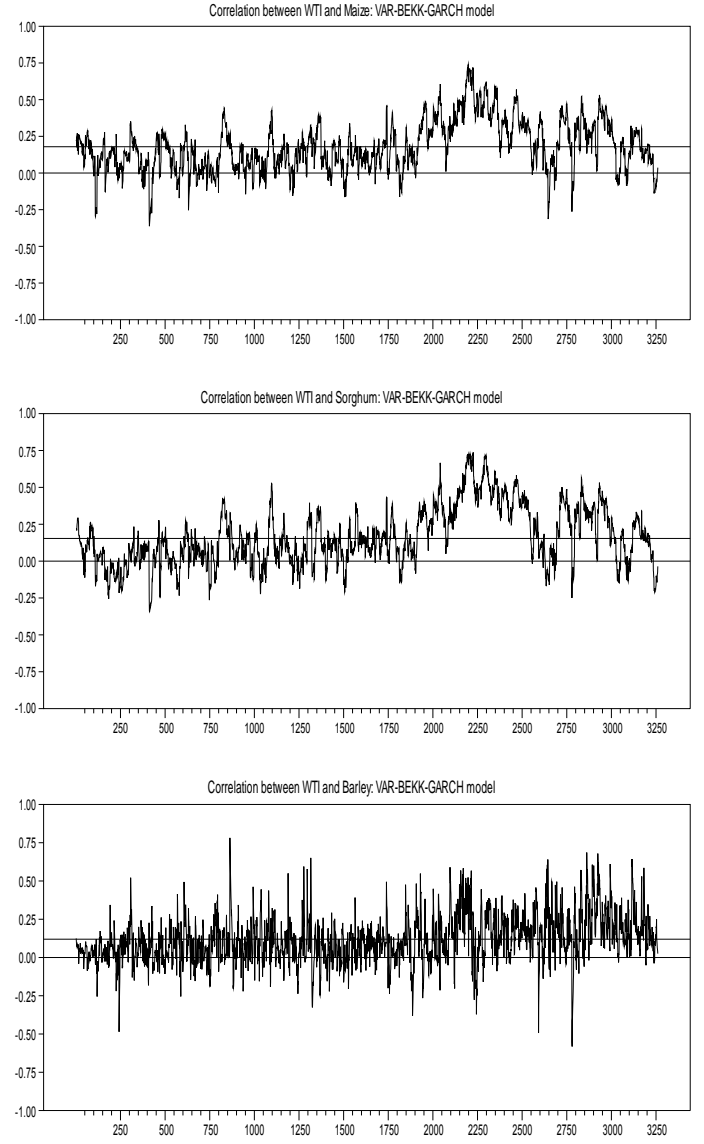

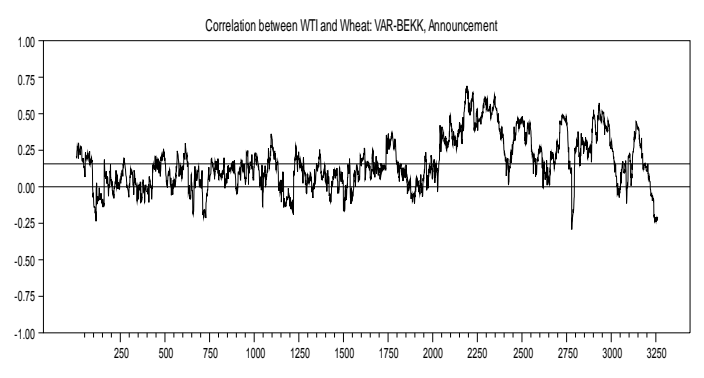

Correlation between WTI and Maize: VAR-BEKK, Announcement
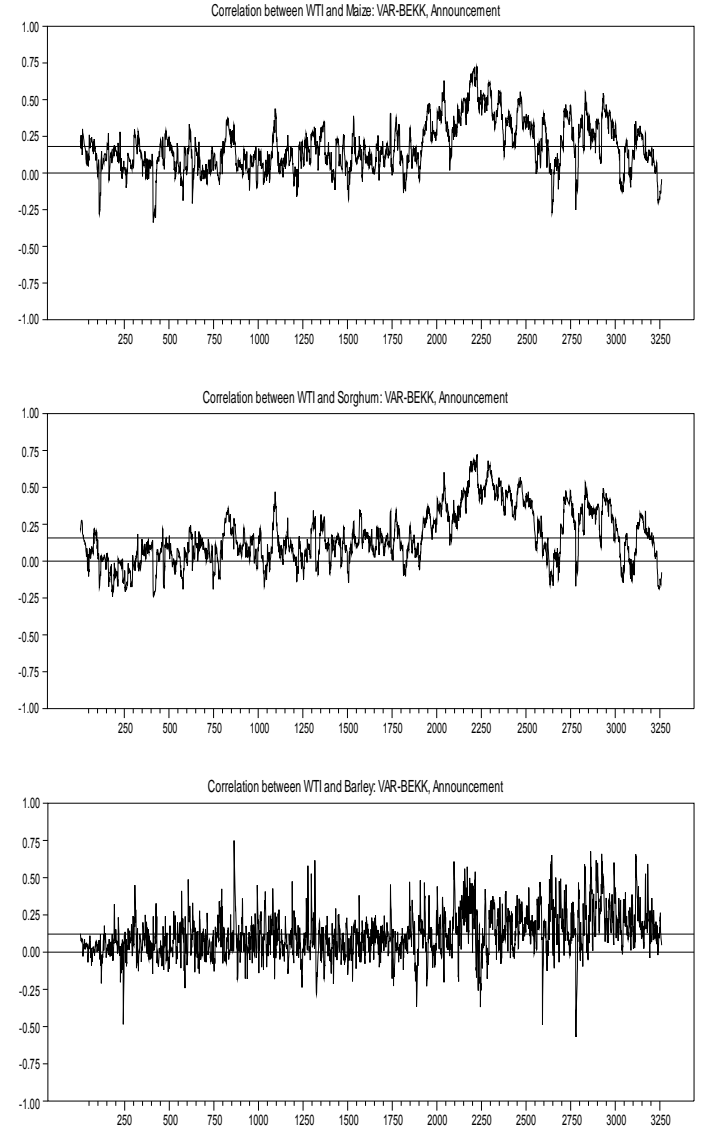

Fig. 3: DCC between the WTI and cereal markets (the VAR-DCC-GARCH model)
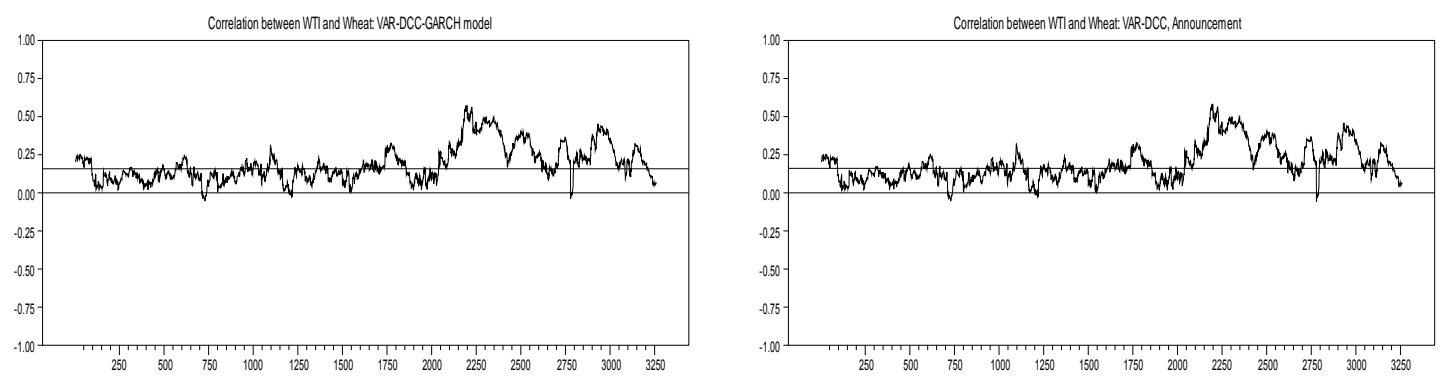

20 

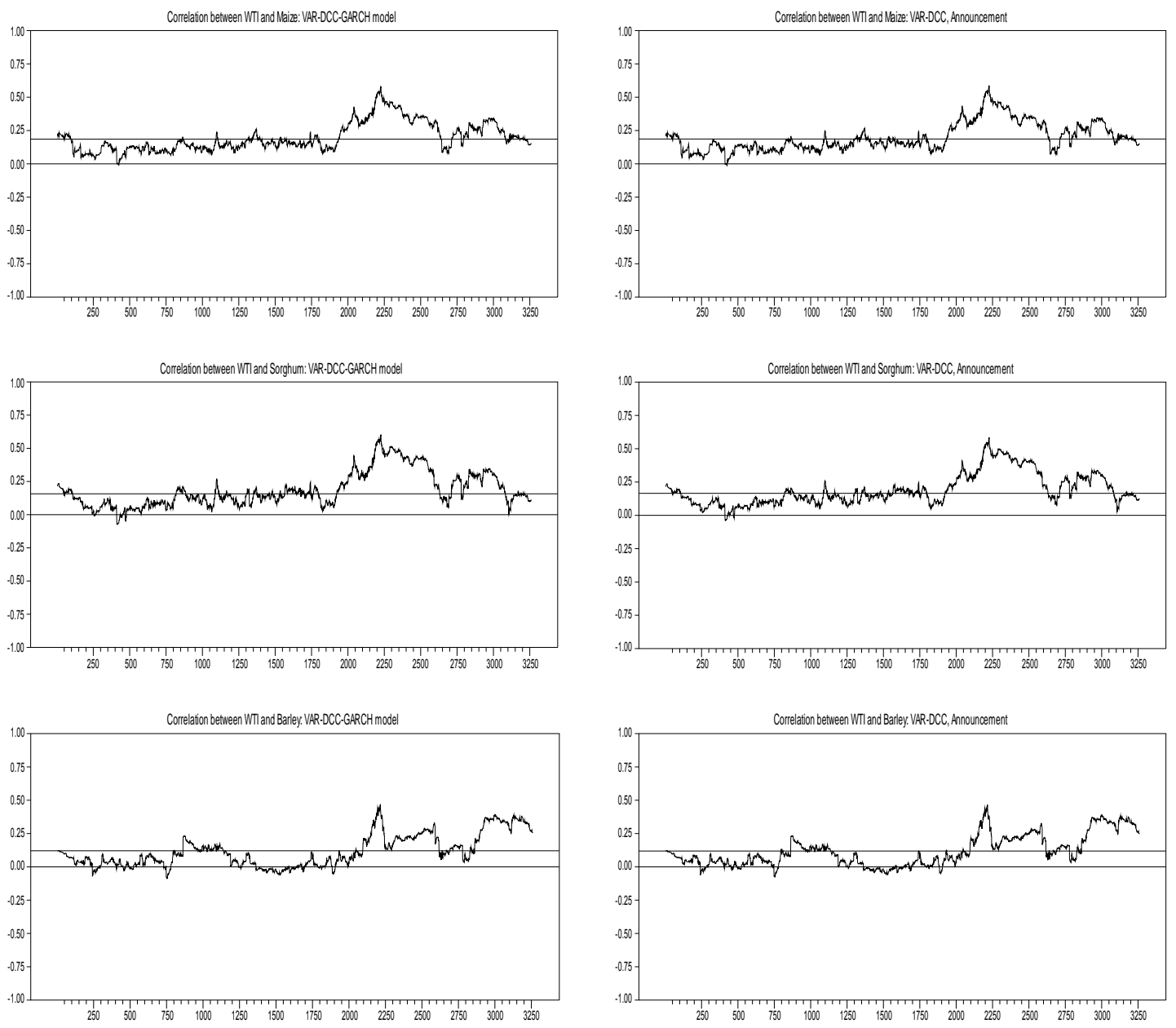

Tables 6-7 give the estimates for the VAR-BEKK-GARCH and the VAR-DCCGARCH models without and with the OPEC news announcements for the Brent market, respectively. As can be seen in Table 6 for the VAR-BEKK-GARCH, the previous cereal returns (with the exception of wheat) influence current cereal returns. Surprisingly, the past Brent returns do not influence the current Brent returns. This finding indicates that the Brent market is weakly efficient. We also find a bidirectional mean spillover across the Brent and corn markets. The past Brent returns can thus be used to forecast barley returns. As to the volatility spillovers, the past shocks and conditional volatility contribute to explain the current conditional volatility in all markets. The past news and conditional volatility of the barley market affect the conditional variance of the Brent market. The results of the VARBEKK-GARCH model with the OPEC news announcements are mostly similar to those without OPEC announcements. In the conditional mean, the cut production decisions have no significant impacts on the cereal and energy returns, while the maintain decisions affect the 
returns of both sorghum and barley. Similarly, the increase decisions may explain the returns of the barley market. As for the WTI market, the past news and conditional volatility affect significantly the current conditional volatility in all cases at the $1 \%$ level. We also find a unidirectional volatility from the wheat and the barley to the Brent markets. In contrast, the past shocks of barley explain the conditional volatility of the crude oil markets. The past conditional volatility of the Brent market also affects significantly the sorghum market.

When the DCC-GARCH model is used (Table 7), dynamic conditional correlations are meaningful as all coefficients are statistically significant and volatility transmission across oil and energy markets is found to be significant. OPEC decisions are more pronounced in the case of the increase and cut decisions. Our results are indeed consistent with those of Abbottetal (2008), Chen et al. (2010), Du et al. (2011), FAO (2008), Hanson et al. (1993), Ji and Fan (2012), Mitchell (2008), Nazlioglu et al. (2013) and Nazlioglu and Soytas (2012), which find strong evidence of volatility spillovers among crude oil and several agricultural commodity markets. Inversely, we invalidate the conclusions of Campiche et al. (2007) and Zhang and Reed (2008). Indeed, Campiche et al. (2007) suggest that the agricultural commodity prices are not significantly dependent on the oil prices until 2006. Over the period January 2000-October 2007, Zhang and Reed (2008) conclude that crude oil prices are not the major factor behind the soar in China's corn, soy metal, and pork prices.

Table 6: Estimation results of VAR-BEKK-GARCH model without and with OPEC news announcements (Brent)

\begin{tabular}{|c|c|c|c|c|c|c|c|c|}
\hline & \multicolumn{2}{|c|}{ Brent-Wheat } & \multicolumn{2}{|c|}{ Brent-Corn } & \multicolumn{2}{|c|}{ Brent - Sorghum } & \multicolumn{2}{|c|}{ Brent - Barley } \\
\hline Coef. & $\begin{array}{c}\text { without } \\
\text { OPEC news }\end{array}$ & $\begin{array}{c}\text { with OPEC } \\
\text { news }\end{array}$ & $\begin{array}{c}\text { without } \\
\text { OPEC news }\end{array}$ & $\begin{array}{c}\text { with OPEC } \\
\text { news }\end{array}$ & $\begin{array}{c}\text { without } \\
\text { OPEC news }\end{array}$ & $\begin{array}{c}\text { with OPEC } \\
\text { news }\end{array}$ & $\begin{array}{c}\text { without } \\
\text { OPEC news }\end{array}$ & $\begin{array}{c}\text { with OPEC } \\
\text { news }\end{array}$ \\
\hline \multicolumn{9}{|c|}{ Panel A:Conditional mean } \\
\hline \multirow{2}{*}{$\mu^{e}$} & 0.090 & 0.087 & 0.084 & 0.080 & 0.084 & 0.089 & 0.100 & 0.098 \\
\hline & $(0.035)^{*}$ & $(0.041 * *$ & $(0.035)^{* *}$ & $(0.037)^{* *}$ & $(0.035)^{* *}$ & $(0.038) * *$ & $(0.036)^{* * *}$ & $(0.038)^{* * *}$ \\
\hline \multirow{2}{*}{$a^{e}$} & 0.002 & -0.001 & 0.004 & 0.001 & 0.005 & 0.005 & 0.001 & -0.001 \\
\hline & $(0.019)$ & $(0.019)$ & $(0.019)$ & $(0.016)$ & $(0.018)$ & $(0.018)$ & $(0.019)$ & $(0.019)$ \\
\hline \multirow{2}{*}{$b^{e}$} & 0.101 & 0.102 & 0.084 & 0.082 & 0.106 & 0.106 & 0.034 & 0.037 \\
\hline & $(0.022) * * *$ & $(0.024)^{* * *}$ & $(0.021)^{* * *}$ & $(0.02) * * *$ & $(0.022)^{* * *}$ & $(0.023)^{* * *}$ & $(0.026)$ & $(0.026)$ \\
\hline \multirow[t]{2}{*}{ cut $^{e}$} & & 0.043 & & -0.087 & & 0.168 & & 0.044 \\
\hline & & $(0.752)$ & & $(0.760)$ & & $(0.749)$ & & $(0.700)$ \\
\hline \multirow[t]{2}{*}{ maintain $^{e}$} & & -0.135 & & -0.250 & & -0.139 & & -0.155 \\
\hline & & $(0.394)$ & & $(0.366)$ & & $(0.320)$ & & $(0.358)$ \\
\hline \multirow[t]{2}{*}{ increase $^{e}$} & & 0.678 & & 0.647 & & 0.556 & & 0.387 \\
\hline & & $(0.642)$ & & $(0.598)$ & & $(0.664)$ & & $(0.756)$ \\
\hline \multirow{2}{*}{$\mu^{c}$} & 0.028 & 0.027 & 0.013 & 0.011 & 0.046 & 0.036 & 0.043 & 0.043 \\
\hline & (0.024) & $(0.026)$ & $(0.023)$ & $(0.028)$ & $(0.022) * *$ & $(0.023)$ & $(0.017)^{* * *}$ & $(0.021)^{* *}$ \\
\hline \multirow{2}{*}{$a^{c}$} & 0.010 & 0.012 & 0.034 & 0.034 & 0.121 & 0.126 & 0.090 & 0.089 \\
\hline & $(0.017)$ & $(0.016)$ & $(0.017)^{*}$ & $(0.017)^{*}$ & $(0.018)^{* * *}$ & $(0.019)^{* * *}$ & $(0.023)^{* * *}$ & $(0.021) * * *$ \\
\hline \multirow[t]{2}{*}{$b^{c}$} & -0.004 & -0.004 & -0.021 & -0.022 & -0.004 & -0.002 & -0.012 & -0.012 \\
\hline & $(0.010)$ & $(0.011)$ & $(0.011)^{*}$ & $(0.012)^{*}$ & $(0.010)$ & (0.009) & $(0.006)^{* *}$ & $(0.008)$ \\
\hline \multirow[t]{2}{*}{$c u t^{c}$} & & 0.158 & & 0.257 & & 0.027 & & -0.103 \\
\hline & & $(0.308)$ & & $(0.365)$ & & (0.264) & & $(0.232)$ \\
\hline \multirow[t]{2}{*}{ maintain $^{c}$} & & -0.060 & & 0.172 & & 0.406 & & 0.356 \\
\hline & & $(0.290)$ & & $(0.243)$ & & $(0.270)$ & & $(0.222)$ \\
\hline
\end{tabular}




\begin{tabular}{|c|c|c|c|c|c|c|c|c|}
\hline increase $^{c}$ & & $\begin{array}{r}0.129 \\
(0.447) \\
\end{array}$ & & $\begin{array}{r}-0.600 \\
(0.462) \\
\end{array}$ & & $\begin{array}{r}-0.446 \\
(0.292) \\
\end{array}$ & & $\begin{array}{r}-0.561 \\
(0.359)^{* *} \\
\end{array}$ \\
\hline Panel B:Co & ditionalvarian & & & & & & & \\
\hline$c_{11}$ & 0.246 & 0.239 & 0.226 & 0.218 & 0.245 & 0.279 & 0.239 & 0.243 \\
\hline & $(0.026) * * *$ & $(0.037) * * *$ & $(0.026) * * *$ & $(0.038) * * *$ & $(0.026)^{* * *}$ & $(0.051)^{* * *}$ & $(0.032)^{* * *}$ & $(0.038) * * *$ \\
\hline$c_{1}$ & -0.043 & -0.064 & -0.088 & -0.110 & -0.057 & -0.046 & 0.288 & 0.308 \\
\hline & (0.034) & $(0.033)^{*}$ & $(0.051)^{*}$ & $(0.058)^{*}$ & $(0.030)^{*}$ & $(0.025)^{*}$ & $(0.079) * * *$ & $(0.088) * * *$ \\
\hline$c_{22}$ & 0.092 & 0.060 & 0.261 & 0.249 & 0.104 & -0.023 & 0.516 & 0.505 \\
\hline & $(0.021) * * *$ & $(0.045)$ & $(0.026)^{* * *}$ & $(0.053)^{* * *}$ & $(0.020)^{* * *}$ & $(0.057)$ & $(0.046)^{* * *}$ & $(0.057) * * *$ \\
\hline$a_{1}$ & 0.220 & 0.210 & 0.202 & 0.190 & 0.202 & 0.220 & 0.202 & 0.196 \\
\hline & $(0.008) * * *$ & $(0.021)^{* * *}$ & $(0.008)^{* * *}$ & $(0.019) * * *$ & $(0.008)^{* * *}$ & $(0.025)^{* * *}$ & $(0.008) * * *$ & $(0.016) * * *$ \\
\hline$a_{12}$ & 0.005 & 0.004 & 0.010 & 0.011 & -0.007 & -0.008 & -0.007 & 0.004 \\
\hline & (0.009) & $(0.007)$ & (0.009) & $(0.010)$ & (0.008) & $(0.006)$ & (0.008) & $(0.012)$ \\
\hline$a_{21}$ & -0.008 & -0.010 & -0.008 & -0.007 & 0.012 & 0.012 & 0.096 & 0.100 \\
\hline & (0.017) & $(0.018)$ & (0.019) & $(0.021)$ & $(0.018)$ & $(0.018)$ & $(0.028) * * *$ & $(0.028) * * *$ \\
\hline$a_{2}$ & 0.176 & 0.173 & 0.257 & 0.256 & 0.263 & 0.209 & 0.538 & 0.571 \\
\hline & $(0.010)^{* * *}$ & $(0.018) * * *$ & $(0.014)^{* * *}$ & $(0.029) * * *$ & $(0.010)^{* * *}$ & $(0.012)^{* * *}$ & $(0.014)^{* * *}$ & $(0.038) * * *$ \\
\hline$b_{1}$ & 0.970 & 0.971 & 0.974 & 0.975 & 0.973 & 0.966 & 0.975 & 0.975 \\
\hline & $(0.003)^{* * *}$ & $(0.005)^{* * *}$ & $(0.003)^{* * *}$ & $(0.005) * * *$ & $(0.003)^{* * *}$ & $(0.008)^{* * *}$ & $(0.003)^{* * *}$ & $(0.004) * * *$ \\
\hline$b_{1}$ & 0.000 & 0.000 & 0.000 & 0.000 & 0.003 & 0.003 & 0.002 & -0.002 \\
\hline & (0.002) & $(0.002)$ & (0.003) & $(0.003)$ & $(0.002)$ & $(0.002)^{*}$ & $(0.005)$ & $(0.006)$ \\
\hline$b_{21}$ & 0.005 & 0.006 & 0.009 & 0.010 & 0.002 & 0.003 & -0.055 & -0.055 \\
\hline & (0.004) & $(0.004)$ & (0.006) & $(0.007)$ & (0.004) & (0.004) & $(0.017) * * *$ & $(0.016) * * *$ \\
\hline$b_{20}$ & 0.982 & 0.983 & 0.953 & 0.953 & 0.965 & 0.976 & 0.769 & 0.752 \\
\hline & $(0.002) * * *$ & $(0.004)^{* * *}$ & $(0.005)^{* * *}$ & $(0.011)^{* * *}$ & $(0.002)^{* * *}$ & $(0.002)^{* * *}$ & $(0.011)^{* * *}$ & $(0.026) * * *$ \\
\hline cut $_{11}$ & & 1.006 & & 1.080 & & 1.084 & & 0.667 \\
\hline & & $(0.394) * *$ & & $(0.364) * * *$ & & $(0.402)^{* * *}$ & & $(0.474)$ \\
\hline cut $_{12}$ & & 0.074 & & 0.094 & & 0.018 & & -0.345 \\
\hline & & $(0.167)$ & & $(0.228)$ & & $(0.126)$ & & $(0.290)$ \\
\hline cut $_{22}$ & & -0.060 & & -0.249 & & 0.023 & & -0.505 \\
\hline & & (0.192) & & $(0.276)$ & & $(0.155)$ & & $(0.310)$ \\
\hline maintain $_{11}$ & & -0.745 & & -0.715 & & -0.826 & & -0.904 \\
\hline & & $(0.286)^{* * *}$ & & $(0.316)^{* *}$ & & $(0.399)^{* *}$ & & $(0.274)^{* * *}$ \\
\hline maintain $_{12}$ & & -0.427 & & -0.146 & & -0.276 & & -1.218 \\
\hline & & $(0.144)^{* * *}$ & & $(0.283)$ & & $(0.452)$ & & $(0.183) * * *$ \\
\hline maintain $_{22}$ & & -0.060 & & -0.249 & & 1.137 & & -0.505 \\
\hline & & $(0.805)$ & & $(0.598)$ & & $(0.180)^{* * *}$ & & $(0.601)$ \\
\hline increase $_{11}$ & & 1.334 & & 1.340 & & 1.283 & & 1.300 \\
\hline & & $(0.314)^{* * *}$ & & $(0.284)^{* * *}$ & & $(0.298)^{* * *}$ & & $(0.306)^{* * *}$ \\
\hline increase $_{12}$ & & 0.093 & & 0.185 & & -0.005 & & -0.433 \\
\hline & & $(0.204)$ & & $(0.262)$ & & $(0.124)$ & & (0.413) \\
\hline increase $_{22}$ & & -0.060 & & -0.249 & & 0.023 & & 0.209 \\
\hline & & $(0.960)$ & & $(0.550)$ & & $(0.162)$ & & $(0.253)$ \\
\hline Panel C: D & gnostic test & & & & & & & \\
\hline $\log L$ & -13096.770 & -13087.944 & -13239.659 & -13230.356 & -13063.742 & -13022.773 & -12524.922 & -12510.035 \\
\hline$H Q(20)$ & 76.968 & 77.596 & 87.506 & 86.165 & 78.748 & 81.867 & 103.986 & 104.875 \\
\hline & {$[0.511]$} & [0.491] & [0.216] & [0.246] & [0.454] & {$[0.360]$} & {$[0.026]^{* *}$} & {$[0.022] * *$} \\
\hline$H Q_{s}(20)$ & 101.489 & 101.641 & 107.075 & 100.241 & 73.651 & 76.376 & 66.946 & 54.246 \\
\hline & {$[0.038]^{* *}$} & {$[0.037]^{* *}$} & {$[0.016]^{* *}$} & {$[0.045]^{* *}$} & {$[0.618]$} & {$[0.530]$} & {$[0.809]$} & [0.981] \\
\hline
\end{tabular}

Note: See notes of Table 4.

Table 7: Estimation results of VAR-DCC-GARCH model without and with OPEC news announcements (Brent)

\begin{tabular}{|c|c|c|c|c|c|c|c|c|}
\hline & \multicolumn{2}{|c|}{ Brent - Wheat } & \multicolumn{2}{|c|}{ Brent - Corn } & \multicolumn{2}{|c|}{ Brent - Sorghum } & \multicolumn{2}{|c|}{ Brent - Barley } \\
\hline Coef. & $\begin{array}{c}\text { without } \\
\text { OPEC news }\end{array}$ & $\begin{array}{c}\text { with OPEC } \\
\text { news }\end{array}$ & $\begin{array}{c}\text { without } \\
\text { OPEC news }\end{array}$ & $\begin{array}{c}\text { with OPEC } \\
\text { news }\end{array}$ & $\begin{array}{c}\text { without } \\
\text { OPEC news }\end{array}$ & $\begin{array}{c}\text { with OPEC } \\
\text { news }\end{array}$ & $\begin{array}{c}\text { without } \\
\text { OPEC news }\end{array}$ & $\begin{array}{c}\text { with OPEC } \\
\text { news }\end{array}$ \\
\hline \multicolumn{9}{|c|}{ Panel A: Conditional mean } \\
\hline$\mu^{e}$ & $\begin{array}{r}0.095 \\
(0.035)^{* * *}\end{array}$ & $\begin{array}{r}0.095 \\
(0.036)^{* * *}\end{array}$ & $\begin{array}{r}0.093 \\
(0.037)^{* *}\end{array}$ & $\begin{array}{r}0.093 \\
(0.035)^{* * *}\end{array}$ & $\begin{array}{r}0.097 \\
(0.038)^{*}\end{array}$ & $\begin{array}{r}0.100 \\
(0.036)^{* * *}\end{array}$ & $\begin{array}{r}0.102 \\
(0.037)^{* * * *}\end{array}$ & $\begin{array}{r}0.104 \\
(0.036)^{* * *}\end{array}$ \\
\hline$a^{e}$ & $\begin{array}{r}0.002 \\
(0.019)\end{array}$ & $\begin{array}{r}0.001 \\
(0.020)\end{array}$ & $\begin{array}{r}0.003 \\
(0.019)\end{array}$ & $\begin{array}{r}0.002 \\
(0.020)\end{array}$ & $\begin{array}{r}0.005 \\
(0.019)\end{array}$ & $\begin{array}{r}0.005 \\
(0.020)\end{array}$ & $\begin{array}{r}-0.001 \\
(0.019)\end{array}$ & $\begin{array}{r}-0.003 \\
(0.019)\end{array}$ \\
\hline$b^{e}$ & $\begin{array}{r}0.098 \\
(0.022)^{* * *}\end{array}$ & $\begin{array}{r}0.097 \\
(0.022)^{* * *}\end{array}$ & $\begin{array}{r}0.084 \\
(0.022)^{* * *}\end{array}$ & $\begin{array}{r}0.083 \\
(0.021)^{* * *}\end{array}$ & $\begin{array}{r}0.100 \\
(0.023)^{* * *}\end{array}$ & $\begin{array}{r}0.098 \\
(0.022)^{* * *}\end{array}$ & $\begin{array}{r}0.036 \\
(0.026)\end{array}$ & $\begin{array}{r}0.037 \\
(0.026)\end{array}$ \\
\hline
\end{tabular}




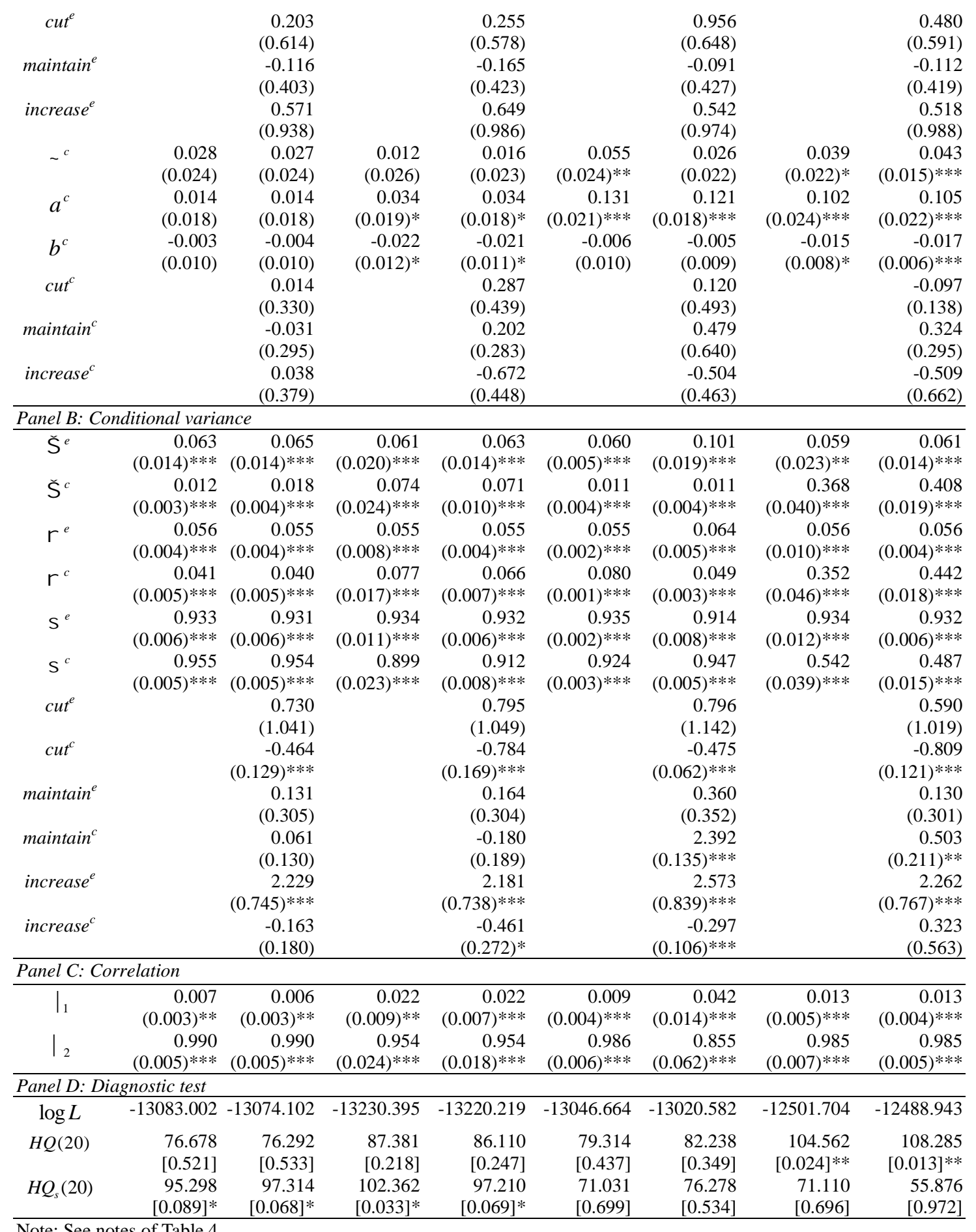

\subsection{Return and volatility spillovers between the heating and cereal markets}

As clearly seen from Table 8, the own past returns in the heating oil and cereal markets (with the exception of wheat) significantly influence the actual commodity returns. Such a result thus reveals some evidence of return predictability. Moreover, the mean spillovers 
across the wheat and heating oil markets are detected. A unidirectional mean spillover is found from the sorghum to the heating oil and from the heating to the corn markets. For the conditional variance, both the oil and cereal markets are affected by their own past shocks and variance. On the other hand, the heating markets generally receive information from the cereal markets, except the sorghum market. We also find that the OPEC news announcements increase the volatility of oil markets. The estimates of the VAR-DCC-GARCH model, reported in Table 9, show evidence of bidirectional mean spillover across heating and wheat and heating and sorghum when dummy variables are introduced. Past news of heating oil affect the current returns of corn markets. We find a significant shock transmission and volatility spillovers between all commodity markets. Interestingly, the cut decisions have a significant impact on both oil and cereal markets. The maintain decisions affect barley markets while the increase decisions influence sorghum markets while the increase decisions have no significant impact, suggesting the lack of credibility in OPEC production quota announcements (Demirer and Kutan, 2012). The results also support the hypothesis of dynamic conditional correlations of commodity markets. The short-run persistence of shocks on the DCC estimates is greatest for wheat and sorghum (0.006) in the case of model without dummy variables. It reaches 0.007 when we consider the dummy variables. The largest long-run persistence of shocks to the DCC estimates is 0.998 for the wheat, corn and sorghum markets.

Table 8: Estimation results of VAR-BEKK-GARCH model without and with OPEC news announcements (Heating oil)

\begin{tabular}{|c|c|c|c|c|c|c|c|c|}
\hline & \multicolumn{2}{|c|}{ Heating -Wheat } & \multicolumn{2}{|c|}{ Heating -Corn } & \multicolumn{2}{|c|}{ Heating - Sorghum } & \multicolumn{2}{|c|}{ Heating - Barley } \\
\hline Coef. & $\begin{array}{c}\text { without } \\
\text { OPEC news }\end{array}$ & $\begin{array}{c}\text { with OPEC } \\
\text { news }\end{array}$ & $\begin{array}{c}\text { without } \\
\text { OPEC news }\end{array}$ & $\begin{array}{c}\text { with OPEC } \\
\text { news }\end{array}$ & $\begin{array}{c}\text { without } \\
\text { OPEC news }\end{array}$ & $\begin{array}{c}\text { with OPEC } \\
\text { news }\end{array}$ & $\begin{array}{c}\text { without } \\
\text { OPEC news }\end{array}$ & $\begin{array}{c}\text { with OPEC } \\
\text { news }\end{array}$ \\
\hline \multicolumn{9}{|c|}{ Panel A: Conditional mean } \\
\hline \multirow[t]{2}{*}{$\mu^{e}$} & 0.086 & 0.077 & 0.090 & 0.081 & 0.095 & 0.091 & 0.108 & 0.100 \\
\hline & $(0.036)^{* *}$ & $(0.037)^{* *}$ & $(0.037) * *$ & $(0.037)^{* *}$ & $(0.036)^{* * *}$ & $(0.041)^{* *}$ & $(0.037) * * *$ & $(0.035)^{* * *}$ \\
\hline \multirow{2}{*}{$a^{e}$} & -0.038 & -0.039 & -0.030 & -0.032 & -0.032 & -0.034 & -0.039 & -0.038 \\
\hline & $(0.013) * * *$ & $(0.014) * * *$ & $(0.016) *$ & $(0.016)^{* *}$ & $(0.017)^{*}$ & $(0.013)^{* *}$ & $(0.018)^{* *}$ & $(0.017)^{* *}$ \\
\hline \multirow{2}{*}{$b^{e}$} & 0.056 & 0.058 & 0.011 & 0.011 & 0.042 & 0.042 & 0.018 & 0.020 \\
\hline & $(0.023)^{* *}$ & $(0.023)^{* *}$ & $(0.022)$ & $(0.022)$ & $(0.023)^{*}$ & $(0.023) *$ & $(0.026)$ & $(0.024)$ \\
\hline \multirow[t]{2}{*}{ cut $^{e}$} & & -0.268 & & -0.196 & & -0.249 & & -0.325 \\
\hline & & $(0.856)$ & & (0.953) & & $(0.923)$ & & (0.990) \\
\hline \multirow[t]{2}{*}{ maintain $^{e}$} & & -0.074 & & -0.147 & & -0.088 & & -0.003 \\
\hline & & (0.398) & & $(0.380)$ & & $(0.334)$ & & $(0.488)$ \\
\hline \multirow[t]{2}{*}{ increase $e^{e}$} & & 1.119 & & 0.986 & & 0.742 & & 0.859 \\
\hline & & $(0.566)^{* *}$ & & $(0.694)$ & & $(0.665)$ & & (1.037) \\
\hline \multirow[t]{2}{*}{$\mu^{c}$} & 0.032 & 0.032 & 0.022 & 0.019 & 0.044 & 0.037 & 0.043 & 0.041 \\
\hline & (0.027) & (0.028) & (0.027) & (0.027) & $(0.024)^{*}$ & $(0.026)$ & $(0.021) * *$ & $(0.013) * * *$ \\
\hline \multirow{2}{*}{$a^{c}$} & 0.023 & 0.025 & 0.038 & 0.039 & 0.126 & 0.136 & 0.083 & 0.101 \\
\hline & $(0.018)$ & $(0.017)$ & $(0.018)^{* *}$ & $(0.017)^{* *}$ & $(0.017)^{* * *}$ & $(0.018)^{* * * *}$ & $(0.024)^{* * *}$ & $(0.021) * * *$ \\
\hline \multirow[t]{2}{*}{$b^{c}$} & -0.019 & -0.019 & -0.016 & -0.016 & -0.009 & -0.011 & 0.000 & -0.001 \\
\hline & $(0.009)^{* *}$ & $(0.009)^{* *}$ & $(0.009)^{*}$ & $(0.010) *$ & $(0.007)$ & (0.007) & (0.006) & $(0.005)$ \\
\hline \multirow[t]{2}{*}{$c u t^{c}$} & & 0.084 & & 0.341 & & 0.055 & & 0.029 \\
\hline & & $(0.344)$ & & $(0.355)$ & & $(0.310)$ & & $(0.423)$ \\
\hline \multirow[t]{2}{*}{ maintain $^{c}$} & & -0.055 & & 0.207 & & 0.358 & & 0.296 \\
\hline & & $(0.276)$ & & $(0.233)$ & & $(0.250)$ & & $(0.305)$ \\
\hline increase $^{c}$ & & 0.062 & & -0.747 & & -0.417 & & -0.509 \\
\hline
\end{tabular}




\begin{tabular}{|c|c|c|c|c|c|c|c|c|}
\hline \multirow{2}{*}{\multicolumn{9}{|c|}{ Panel B:Conditionalvariance }} \\
\hline & & & & & & & & \\
\hline \multirow{2}{*}{$c_{11}$} & 0.286 & 0.293 & 0.285 & 0.295 & 0.300 & 0.324 & 0.279 & 0.286 \\
\hline & $(0.042)^{* * *}$ & $(0.043)^{* * *}$ & $(0.040)^{* * *}$ & $(0.041)^{* * *}$ & $(0.041)^{* * *}$ & $(0.040)^{* * *}$ & $(0.033)^{* * *}$ & $(0.031)^{* * *}$ \\
\hline \multirow{2}{*}{$c_{12}$} & -0.049 & -0.071 & -0.049 & -0.072 & -0.048 & -0.031 & 0.344 & 0.376 \\
\hline & $(0.030)$ & $(0.031)^{* *}$ & $(0.041)$ & $(0.046)$ & $(0.026)^{*}$ & $(0.022)$ & $(0.078)^{* * *}$ & $(0.091)^{* * *}$ \\
\hline \multirow{2}{*}{$c_{22}$} & -0.084 & 0.032 & -0.176 & 0.164 & 0.109 & -0.040 & 0.567 & 0.601 \\
\hline & $(0.022)^{* * *}$ & $(0.083)$ & $(0.027)^{* * *}$ & $(0.034)^{* * *}$ & $(0.021)^{* * *}$ & $(0.023)^{*}$ & $(0.049) * * *$ & $(0.058) * * *$ \\
\hline \multirow{2}{*}{$a_{11}$} & 0.295 & 0.295 & 0.286 & 0.286 & 0.278 & 0.284 & 0.258 & 0.252 \\
\hline & $(0.019)^{* * * *}$ & $(0.018)^{* * *}$ & $(0.019) * * *$ & $(0.017)^{* * *}$ & $(0.019)^{* * *}$ & $(0.019) * * *$ & $(0.014)^{* * *}$ & $(0.008) * * *$ \\
\hline \multirow{2}{*}{$a_{12}$} & 0.000 & -0.001 & -0.004 & -0.003 & -0.002 & -0.004 & -0.011 & -0.015 \\
\hline & (0.004) & (0.005) & $(0.006)$ & $(0.006)$ & $(0.004)$ & $(0.004)$ & $(0.006)^{*}$ & $(0.004)^{* * *}$ \\
\hline \multirow{2}{*}{$a_{21}$} & -0.067 & -0.074 & -0.041 & -0.042 & -0.024 & -0.033 & 0.066 & $\quad 0.080$ \\
\hline & $(0.020)^{* * *}$ & $(0.020)^{* * *}$ & $(0.021)^{* *}$ & $(0.021)^{*}$ & $(0.022)$ & $(0.022)$ & $(0.032)^{* *}$ & $(0.031)^{* *}$ \\
\hline \multirow{2}{*}{$a_{22}$} & 0.169 & 0.163 & 0.189 & 0.190 & 0.249 & 0.207 & 0.591 & 0.719 \\
\hline & $(0.013)^{* * *}$ & $(0.014)^{* * *}$ & $(0.015)^{* * *}$ & $(0.015)^{* * *}$ & $(0.015)^{* * *}$ & $(0.010)^{* * *}$ & $(0.041)^{* * *}$ & $(0.012) * * *$ \\
\hline \multirow{2}{*}{$b_{11}$} & 0.949 & 0.945 & 0.951 & 0.948 & 0.953 & 0.948 & 0.962 & 0.961 \\
\hline & $(0.007)^{* * *}$ & $(0.006)^{* * *}$ & $(0.006)^{* * *}$ & $(0.006)^{* * *}$ & $(0.006)^{* * *}$ & $(0.007) * * *$ & $(0.004)^{* * *}$ & $(0.003)^{* * *}$ \\
\hline \multirow[t]{2}{*}{$b_{12}$} & 0.001 & 0.001 & 0.001 & 0.001 & 0.001 & 0.001 & 0.001 & 0.002 \\
\hline & $(0.001)$ & $(0.001)$ & $(0.002)$ & $(0.002)$ & $(0.001)$ & $(0.001)$ & $(0.004)$ & $(0.006)$ \\
\hline \multirow{2}{*}{$b_{21}$} & 0.020 & 0.023 & 0.016 & 0.020 & 0.013 & 0.015 & -0.054 & -0.065 \\
\hline & $(0.005)^{* * *}$ & $(0.005)^{* * *}$ & $(0.006)^{* * *}$ & $(0.006)^{* * *}$ & $(0.006)^{* *}$ & $(0.005)^{* * *}$ & $(0.020)^{* * *}$ & $(0.022)^{* * *}$ \\
\hline \multirow{2}{*}{$b_{22}$} & 0.984 & 0.985 & 0.976 & 0.976 & 0.969 & 0.976 & 0.712 & 0.627 \\
\hline & $(0.003)^{* * *}$ & $(0.003)^{* * *}$ & $(0.004)^{* * *}$ & $(0.004)^{* * *}$ & $(0.003)^{* * *}$ & $(0.002)^{* * *}$ & $(0.032) * * *$ & $(0.012) * * *$ \\
\hline \multirow[t]{2}{*}{ cut $_{11}$} & & 2.168 & & 2.087 & & 2.082 & & 1.554 \\
\hline & & $(0.419)^{* * *}$ & & $(0.382) * * *$ & & $(0.384)^{* * *}$ & & $(0.406) * * *$ \\
\hline \multirow[t]{2}{*}{ cut $_{12}$} & & 0.172 & & 0.177 & & 0.028 & & -0.769 \\
\hline & & $(0.139)$ & & (0.169) & & $(0.134)$ & & (1.087) \\
\hline \multirow[t]{2}{*}{$\mathrm{cut}_{22}$} & & -0.032 & & -0.164 & & 0.040 & & -0.607 \\
\hline & & $(0.191)$ & & $(0.200)$ & & (0.149) & & (76.66) \\
\hline \multirow[t]{2}{*}{ maintain $_{11}$} & & -1.089 & & -1.181 & & -0.334 & & -1.065 \\
\hline & & $(0.325)^{* * *}$ & & $(0.303)^{* * *}$ & & $(0.353)$ & & $(0.298) * * *$ \\
\hline \multirow[t]{2}{*}{ maintain $_{12}$} & & -0.206 & & -0.147 & & 1.051 & & -1.251 \\
\hline & & $(0.277)$ & & $(0.233)$ & & $(0.096)^{* * *}$ & & (0.816) \\
\hline \multirow[t]{2}{*}{ maintain $_{22}$} & & -0.491 & & 0.086 & & 0.620 & & -0.019 \\
\hline & & $(0.235)^{* *}$ & & $(0.400)$ & & $(0.150)^{* * *}$ & & (1.022) \\
\hline \multirow[t]{2}{*}{ increase $_{11}$} & & 0.805 & & 0.780 & & 0.717 & & 0.680 \\
\hline & & $(0.553)$ & & $(0.535)$ & & $(0.590)$ & & (0.539) \\
\hline \multirow[t]{2}{*}{ increase $_{12}$} & & 0.065 & & -0.009 & & -0.042 & & -0.696 \\
\hline & & $(0.319)$ & & $(0.301)$ & & $(0.163)$ & & (1.838) \\
\hline \multirow[t]{2}{*}{ increase $_{22}$} & & 0.092 & & -0.164 & & 0.040 & & -1.491 \\
\hline & & $(0.634)$ & & $(0.387)$ & & $(0.160)$ & & $(0.998)$ \\
\hline anel $C: D i$ & lostic test & & & & & & & \\
\hline $\log L$ & -13210.721 & -13195.988 & -13379.370 & -13364.787 & -13198.595 & -13150.984 & -12691.640 & -12680.253 \\
\hline$H Q(20)$ & 81.993 & 83.709 & 73.644 & 73.737 & 89.384 & 92.816 & 90.461 & 93.147 \\
\hline & {$[0.356]$} & {$[0.308]$} & [0.618] & [0.615] & [0.177] & {$[0.121]$} & {$[0.158]$} & [0.116] \\
\hline$H Q_{s}(20)$ & 96.843 & 101.784 & 74.259 & 76.626 & 78.477 & 86.459 & 57.859 & 66.569 \\
\hline & {$[0.072]^{*}$} & {$[0.036]^{* *}$} & [0.599] & {$[0.522]$} & {$[0.463]$} & {$[0.240]$} & [0.957] & [0.819] \\
\hline
\end{tabular}

Notes: See notes of Table 4.

Table 9: Estimation results of VAR-DCC-GARCH model without and with OPEC news announcements (Heating oil)

\begin{tabular}{|c|c|c|c|c|c|c|c|c|}
\hline \multirow[b]{2}{*}{ Coef. } & \multicolumn{2}{|c|}{ Heating - Wheat } & \multicolumn{2}{|c|}{ Heating - Corn } & \multicolumn{2}{|c|}{ Heating - Sorghum } & \multicolumn{2}{|c|}{ Heating - Barley } \\
\hline & $\begin{array}{c}\text { without } \\
\text { OPEC news }\end{array}$ & $\begin{array}{c}\text { with OPEC } \\
\text { news }\end{array}$ & $\begin{array}{c}\text { without } \\
\text { OPEC news }\end{array}$ & $\begin{array}{c}\text { with OPEC } \\
\text { news }\end{array}$ & $\begin{array}{c}\text { without } \\
\text { OPEC news }\end{array}$ & $\begin{array}{c}\text { with OPEC } \\
\text { news }\end{array}$ & $\begin{array}{c}\text { without } \\
\text { OPEC news }\end{array}$ & $\begin{array}{c}\text { with OPEC } \\
\text { news }\end{array}$ \\
\hline \multicolumn{9}{|c|}{ Panel A: Conditional mean } \\
\hline \multirow[t]{2}{*}{$\mu^{e}$} & 0.090 & 0.083 & 0.088 & 0.082 & 0.096 & 0.073 & 0.099 & 0.0 \\
\hline & $(0.035)^{* * *}$ & $(0.035)^{* * *}$ & $(0.035)^{* *}$ & $(0.035) * *$ & $(0.035)^{* * * *}$ & $(0.034) * *$ & $(0.035)^{* * *}$ & $(0.035)^{* * *}$ \\
\hline \multirow{2}{*}{$a^{e}$} & -0.037 & -0.038 & -0.031 & -0.031 & -0.031 & -0.032 & -0.039 & -0.039 \\
\hline & $(0.018) * *$ & $(0.018)^{* *}$ & $(0.018)^{*}$ & $(0.018)^{*}$ & $(0.018)^{*}$ & (0.019) & $(0.018) * *$ & $(0.018)^{* * *}$ \\
\hline \multirow[t]{2}{*}{$b^{e}$} & 0.046 & 0.046 & 0.004 & 0.004 & 0.032 & 0.015 & 0.016 & 0.01 \\
\hline & $(0.022)^{* *}$ & $(0.022)^{* * *}$ & $(0.022)$ & $(0.021)$ & $(0.022)$ & $(0.023)^{*}$ & $(0.024)$ & $(0.02$ \\
\hline \multirow[t]{2}{*}{$c u t^{e}$} & & -0.320 & & -0.140 & & -0.265 & & 0.08 \\
\hline & & (0.849) & & (0.834) & & (0.694) & & (0.800) \\
\hline maintain $^{e}$ & & -0.055 & & -0.112 & & -0.142 & & -0.042 \\
\hline
\end{tabular}




\begin{tabular}{|c|c|c|c|c|c|c|c|c|}
\hline & & & & & & & & \\
\hline & & $(0.435)$ & & $(0.457)$ & & $(0.427)$ & & $(0.450)$ \\
\hline increase $^{e}$ & & 0.963 & & 1.021 & & 0.800 & & 1.000 \\
\hline & & $(0.787)$ & & $(0.773)$ & & $(0.623)$ & & $(0.812)$ \\
\hline$\mu^{c}$ & 0.028 & 0.027 & 0.010 & 0.014 & 0.057 & -0.013 & 0.041 & 0.046 \\
\hline & (0.024) & (0.024) & $(0.022)$ & $(0.022)$ & $(0.021)^{* * *}$ & $(0.000)^{* * *}$ & $(0.014)^{* * *}$ & $(0.014)^{* * *}$ \\
\hline$a^{c}$ & 0.019 & 0.020 & 0.035 & 0.035 & 0.134 & 0.072 & 0.093 & 0.089 \\
\hline & (0.018) & $(0.018)$ & $(0.018)^{* *}$ & $(0.018)^{* *}$ & $(0.018)^{* * *}$ & $(0.001)^{* * *}$ & $(0.022) * * *$ & $(0.022)^{* * *}$ \\
\hline$b^{c}$ & -0.021 & -0.021 & -0.019 & -0.020 & -0.009 & -0.012 & -0.002 & -0.003 \\
\hline & $(0.009)^{* *}$ & $(0.009)^{* *}$ & $(0.010)^{*}$ & $(0.010)^{*}$ & (0.008) & $(0.007)^{*}$ & $(0.006)$ & $(0.005)$ \\
\hline $\mathrm{cut}^{c}$ & & -0.011 & & 0.266 & & 0.153 & & -0.063 \\
\hline & & (0.309) & & $(0.439)$ & & $(0.077) * *$ & & $(0.059)$ \\
\hline maintain $^{c}$ & & -0.025 & & 0.186 & & 0.327 & & 0.302 \\
\hline & & $(0.298)$ & & $(0.271)$ & & $(0.255)$ & & $(0.303)$ \\
\hline increase $^{c}$ & & 0.034 & & -0.709 & & -0.494 & & -0.574 \\
\hline & & $(0.382)$ & & $(0.417)^{*}$ & & $(0.038)^{* * *}$ & & $(0.590)$ \\
\hline Panel B: Co & tional varianc & & & & & & & \\
\hline$\omega^{e}$ & 0.086 & 0.096 & 0.083 & 0.093 & 0.085 & 0.116 & 0.080 & 0.089 \\
\hline & $(0.017)^{* * *}$ & $(0.019)^{* * *}$ & $(0.017) * * *$ & $(0.019)^{* * *}$ & $(0.017)^{* * *}$ & $(0.014)^{* * *}$ & $(0.017)^{* * * *}$ & $(0.018) * * *$ \\
\hline$\omega^{c}$ & 0.013 & 0.018 & 0.081 & 0.085 & 0.011 & 0.205 & 0.384 & 0.385 \\
\hline & $(0.003)^{* * *}$ & $(0.004)^{* * *}$ & $(0.011)^{* * *}$ & $(0.011)^{* * *}$ & $(0.002)^{* * *}$ & $(0.005)^{* * *}$ & $(0.018)^{* * *}$ & $(0.019) * * *$ \\
\hline$\alpha^{e}$ & 0.085 & 0.086 & 0.087 & 0.089 & 0.086 & 0.091 & 0.087 & 0.089 \\
\hline & $(0.006)^{* * *}$ & $(0.006)^{* * *}$ & $(0.006) * * *$ & $(0.006)^{* * *}$ & $(0.006)^{* * *}$ & $(0.007)^{* * *}$ & $(0.006)^{* * *}$ & $(0.006) * * *$ \\
\hline$\alpha^{c}$ & 0.042 & 0.041 & 0.085 & 0.079 & 0.083 & 0.131 & 0.366 & 0.397 \\
\hline$\alpha$ & $(0.005)^{* * *}$ & $(0.005)^{* * *}$ & $(0.008) * * *$ & $(0.008)^{* * *}$ & $(0.005)^{* * *}$ & $(0.004)^{* * *}$ & $(0.013) * * *$ & $(0.014) * * *$ \\
\hline$\beta^{e}$ & 0.903 & 0.895 & 0.901 & 0.894 & 0.902 & 0.886 & 0.902 & 0.895 \\
\hline$p$ & $(0.007)^{* * * *}$ & $(0.008)^{* * *}$ & $(0.007) * * *$ & $(0.008)^{* * *}$ & $(0.007)^{* * *}$ & $(0.005)^{* * *}$ & $(0.007)^{* * * *}$ & $(0.008) * * *$ \\
\hline$\beta^{c}$ & 0.953 & 0.953 & 0.888 & 0.895 & 0.922 & 0.813 & 0.525 & 0.514 \\
\hline P & $(0.005)^{* * *}$ & $(0.005)^{* * *}$ & $(0.009) * * *$ & $(0.009)^{* * *}$ & $(0.004)^{* * *}$ & $(0.000)^{* * *}$ & $(0.014) * * *$ & $(0.014) * * *$ \\
\hline cut $^{e}$ & 4.960 & $(1.870)^{* * *}$ & 4.911 & $(1.894)^{* * *}$ & 6.791 & $(2.745)^{* *}$ & 4.821 & $(1.768)^{* * * *}$ \\
\hline cut $^{c}$ & -0.470 & $(0.131)^{* * *}$ & -0.876 & $(0.180)^{* * *}$ & -1.366 & $(0.022)^{* * *}$ & -0.804 & $(0.169)^{* * *}$ \\
\hline maintain $^{e}$ & 0.514 & $(0.460)$ & 0.566 & $(0.458)$ & 0.431 & $(0.599)$ & 0.525 & $(0.462)$ \\
\hline maintain $^{c}$ & 0.077 & $(0.132)$ & -0.194 & $(0.204)$ & -0.266 & $(0.351)$ & 0.510 & $(0.201)^{* *}$ \\
\hline increase $^{e}$ & 0.632 & $(0.990)$ & 0.472 & $(0.938)$ & 0.661 & (1.048) & 0.543 & (0.999) \\
\hline increase $^{c}$ & -0.154 & $(0.178)$ & -0.415 & $(0.308)$ & -1.268 & $(0.021)^{* * *}$ & 0.265 & $(0.507)$ \\
\hline Panel C: Co & ation & & & & & & & \\
\hline$\kappa_{1}$ & 0.006 & 0.007 & 0.005 & 0.005 & 0.006 & 0.007 & 0.058 & 0.064 \\
\hline $\mathrm{n}_{1}$ & $(0.003)^{* *}$ & $(0.003)^{* *}$ & $(0.002)^{* *}$ & $(0.002)^{* *}$ & $(0.003) * *$ & $(0.003)^{* *}$ & $(0.024) * *$ & $(0.025)^{* *}$ \\
\hline$\kappa_{2}$ & 0.992 & 0.991 & 0.993 & 0.993 & 0.992 & 0.991 & 0.764 & 0.726 \\
\hline$n_{2}$ & $(0.004)^{* * *}$ & $(0.004)^{* * *}$ & $(0.003)^{* * *}$ & $(0.003) * * *$ & $(0.003)^{* * *}$ & $(0.004)^{* * *}$ & $(0.112)^{* * *}$ & $(0.126) * * *$ \\
\hline Panel D: Di & lostic test & & & & & & & \\
\hline $\log L$ & -13200.945 & -13187.52 & -13351.484 & -13336.661 & -13168.469 & -13217.009 & -12681.289 & -12660.982 \\
\hline$H Q(20)$ & 82.744 & 83.372 & 75.430 & 75.288 & 91.196 & 87.418 & 92.225 & 93.985 \\
\hline & [0.335] & [0.317] & {$[0.561]$} & [0.565] & [0.145] & {$[0.218]$} & [0.129] & [0.104] \\
\hline$H Q_{s}(20)$ & 85.401 & 87.683 & 63.683 & 64.388 & 68.872 & 86.725 & 41.084 & 42.431 \\
\hline & {$[0.265]$} & {$[0.212]$} & {$[0.879]$} & [0.865] & {$[0.760]$} & {$[0.233]$} & [0.999] & [0.999] \\
\hline
\end{tabular}

Notes: See notes of Table 4.

\subsection{Return and volatility spillovers between gasoline and cereal markets}

Table 10 shows that past returns of gasoline and cereal do not affect current gasoline returns. In general, past returns of the cereal markets can be used to forecast actual returns, except the wheat market. Regarding the extent of cross-market volatility transmission, the results show that both past shock and past volatility are important determinants of the current conditional volatility of gasoline and cereal markets. Past shocks of gasoline also affect corn markets, while past shocks of wheat influence the gasoline market. The past volatility of gasoline drives the volatility of the corn market, and the past volatility of cereals affects the conditional volatility of the gasoline market. The estimates of the BEKK-GARCH model with 
exogenous dummy variables in Table 10 show that OPEC news announcements have significant impacts on the volatility of the gasoline market, while the increase decisions affect the barley market. We also find evidence of a unidirectional volatility transmission from the gasoline market to the sorghum market and the past volatility of gasoline significantly affects the conditional volatility of the sorghum and barley markets. Our results are, however, not in line with those of Zhang et al. (2010).

Table 11 reports the estimation results of the DCC-GARCH model for gasoline and cereal markets, without and with OPEC announcements. Some interesting facts can be noted. First, past cereal returns affect the current cereal returns with the exception of the wheat market. Second, there is a unidirectional influence from gasoline to both wheat and barley markets. Finally, the DCC specification for gasoline and sorghum markets is rejected, suggesting the stability of cross-market correlation structure.

Table 10: Estimation results of VAR-BEKK-GARCH model without and with OPEC news announcements (Gasoline)

\begin{tabular}{|c|c|c|c|c|c|c|c|c|}
\hline & \multicolumn{2}{|c|}{ Gasoline -Wheat } & \multicolumn{2}{|c|}{ Gasoline -Corn } & \multicolumn{2}{|c|}{ Gasoline - Sorghum } & \multicolumn{2}{|c|}{ Gasoline - Barley } \\
\hline Coef. & $\begin{array}{c}\text { without } \\
\text { OPEC news }\end{array}$ & $\begin{array}{c}\text { with OPEC } \\
\text { news }\end{array}$ & $\begin{array}{c}\text { without } \\
\text { OPEC news }\end{array}$ & $\begin{array}{c}\text { with OPEC } \\
\text { news }\end{array}$ & $\begin{array}{c}\text { without } \\
\text { OPEC news }\end{array}$ & $\begin{array}{c}\text { with OPEC } \\
\text { news }\end{array}$ & $\begin{array}{c}\text { without } \\
\text { OPEC news }\end{array}$ & $\begin{array}{c}\text { with OPEC } \\
\text { news }\end{array}$ \\
\hline \multicolumn{9}{|c|}{ Panel A:Conditional mean } \\
\hline \multirow[t]{2}{*}{$\mu^{e}$} & 0.099 & 0.098 & 0.096 & 0.098 & 0.094 & 0.098 & 0.101 & 0.097 \\
\hline & $(0.046)^{* *}$ & $(0.043)^{* *}$ & $(0.049) *$ & $(0.049)^{* *}$ & $(0.048) *$ & $(0.045)^{* *}$ & $(0.052) *$ & $(0.049) * *$ \\
\hline \multirow{2}{*}{$a^{e}$} & 0.024 & 0.021 & 0.026 & 0.024 & 0.029 & 0.027 & 0.020 & 0.015 \\
\hline & $(0.017)$ & $(0.018)$ & $(0.017)$ & $(0.016)$ & $(0.017)^{*}$ & $(0.017)$ & $(0.016)$ & $(0.016)$ \\
\hline \multirow{2}{*}{$b^{e}$} & 0.008 & 0.009 & -0.030 & -0.036 & 0.002 & 0.001 & -0.013 & -0.012 \\
\hline & $(0.027)$ & $(0.026)$ & $(0.028)$ & $(0.028)$ & $(0.031)$ & $(0.027)$ & $(0.031)$ & $(0.032)$ \\
\hline \multirow[t]{2}{*}{$c u t^{e}$} & & -0.425 & & -0.539 & & -0.583 & & -0.569 \\
\hline & & $(1.040)$ & & $(0.641)$ & & $(0.964)$ & & $(0.970)$ \\
\hline \multirow[t]{2}{*}{ maintain $^{e}$} & & -0.241 & & -0.285 & & -0.250 & & -0.123 \\
\hline & & $(0.498)$ & & $(0.361)$ & & $(0.406)$ & & $(0.412)$ \\
\hline \multirow[t]{2}{*}{ increase $^{e}$} & & 0.602 & & 0.407 & & 0.246 & & 0.314 \\
\hline & & $(0.760)$ & & $(1.009)$ & & $(0.990)$ & & $(0.858)$ \\
\hline \multirow[t]{2}{*}{$\mu^{c}$} & 0.023 & 0.023 & 0.011 & 0.009 & 0.036 & 0.029 & 0.041 & 0.045 \\
\hline & $(0.026)$ & $(0.027)$ & $(0.027)$ & $(0.028)$ & $(0.024)$ & $(0.022)$ & $(0.023)^{*}$ & $(0.021)^{* *}$ \\
\hline \multirow{2}{*}{$a^{c}$} & 0.023 & 0.024 & 0.037 & 0.037 & 0.128 & 0.135 & 0.094 & 0.093 \\
\hline & $(0.018)$ & $(0.017)$ & $(0.018) * *$ & $(0.017)^{* *}$ & $(0.020)^{* * *}$ & $(0.020)^{* * *}$ & $(0.024)^{* * *}$ & $(0.024) * * *$ \\
\hline \multirow[t]{2}{*}{$b^{c}$} & -0.016 & -0.016 & -0.008 & -0.009 & -0.005 & -0.001 & -0.015 & -0.017 \\
\hline & $(0.009) *$ & $(0.009)^{*}$ & $(0.009)$ & $(0.009)$ & $(0.008)$ & $(0.007)$ & $(0.007) * *$ & $(0.007) * *$ \\
\hline \multirow[t]{2}{*}{$c u t^{c}$} & & 0.069 & & 0.268 & & 0.030 & & -0.134 \\
\hline & & $(0.321)$ & & $(0.386)$ & & $(0.296)$ & & $(0.258)$ \\
\hline \multirow[t]{2}{*}{ maintain $^{c}$} & & -0.067 & & 0.213 & & 0.355 & & 0.287 \\
\hline & & $(0.283)$ & & $(0.229)$ & & $(0.280)$ & & $(0.195)$ \\
\hline \multirow[t]{2}{*}{ increase $^{c}$} & & 0.055 & & -0.802 & & -0.462 & & -0.573 \\
\hline & & $(0.454)$ & & $(0.467)^{*}$ & & $(0.302)$ & & $(0.355)$ \\
\hline \multicolumn{9}{|c|}{ Panel B:Conditional variance } \\
\hline \multirow{2}{*}{$c_{11}$} & 0.418 & 0.481 & 0.408 & 0.468 & 0.429 & 0.496 & 0.371 & 0.384 \\
\hline & $(0.065)^{* * *}$ & $(0.071)^{* * *}$ & $(0.063)^{* * *}$ & $(0.079)^{* * *}$ & $(0.068)^{* * *}$ & $(0.076)^{* * *}$ & $(0.051)^{* * *}$ & $(0.050)^{* * *}$ \\
\hline \multirow{2}{*}{$c_{12}$} & -0.036 & -0.046 & -0.056 & -0.076 & -0.014 & -0.026 & 0.338 & 0.352 \\
\hline & $(0.030)$ & $(0.025)^{*}$ & $(0.042)$ & $(0.042)^{*}$ & $(0.031)$ & $(0.023)$ & $(0.130)^{* * *}$ & $(0.105)^{* * *}$ \\
\hline \multirow{2}{*}{$c_{22}$} & 0.088 & 0.059 & 0.174 & 0.169 & 0.114 & 0.040 & 0.559 & 0.527 \\
\hline & $(0.021)^{* * *}$ & $(0.030) * *$ & $(0.025)^{* * *}$ & $(0.029) * * *$ & $(0.017)^{* * *}$ & $(0.026)$ & $(0.078)^{* * *}$ & $(0.073) * * *$ \\
\hline \multirow{2}{*}{$a_{11}$} & 0.265 & 0.270 & 0.256 & 0.262 & 0.249 & 0.261 & 0.227 & 0.215 \\
\hline & $(0.021)^{* * *}$ & $(0.020)^{* * *}$ & $(0.018)^{* * *}$ & $(0.023)^{* * *}$ & $(0.021)^{* * *}$ & $(0.023)^{* * *}$ & $(0.017)^{* * *}$ & $(0.017) * * *$ \\
\hline$a_{12}$ & -0.001 & -0.003 & -0.015 & -0.016 & -0.007 & -0.011 & -0.001 & 0.002 \\
\hline
\end{tabular}




\begin{tabular}{|c|c|c|c|c|c|c|c|c|}
\hline \multirow{3}{*}{$a_{21}$} & $(0.006)$ & $(0.006)$ & $(0.007)^{* *}$ & $(0.007)^{* *}$ & (0.006) & $(0.006)^{*}$ & $(0.007)$ & (0.007) \\
\hline & -0.053 & -0.062 & -0.027 & -0.034 & -0.019 & -0.028 & 0.055 & 0.056 \\
\hline & $(0.023) * *$ & $(0.024) * * *$ & $(0.024)$ & $(0.026)$ & (0.026) & $(0.025)$ & $(0.035)$ & $(0.036)$ \\
\hline \multirow{2}{*}{$a_{22}$} & 0.171 & 0.164 & 0.198 & 0.201 & 0.249 & 0.209 & 0.591 & 0.613 \\
\hline & $(0.014) * * *$ & $(0.014)^{* * *}$ & $(0.016)^{* * *}$ & $(0.017)^{* * *}$ & $(0.016)^{* * *}$ & $(0.012)^{* * *}$ & $(0.039)^{* * *}$ & $(0.036)^{* * *}$ \\
\hline \multirow{2}{*}{$b_{11}$} & 0.953 & 0.945 & 0.956 & 0.948 & 0.957 & 0.947 & 0.966 & 0.966 \\
\hline & $(0.008) * * *$ & $(0.010)^{* * *}$ & $(0.007) * * *$ & $(0.010) * * *$ & $(0.008)^{* * *}$ & $(0.010)^{* * *}$ & $(0.005)^{* * *}$ & $(0.005)^{* * *}$ \\
\hline \multirow[t]{2}{*}{$b_{12}$} & 0.001 & 0.002 & 0.005 & 0.006 & 0.001 & 0.003 & -0.008 & -0.011 \\
\hline & $(0.002)$ & $(0.002)$ & $(0.002)^{* *}$ & $(0.003)^{* *}$ & $(0.002)$ & $(0.002)^{*}$ & $(0.006)$ & $(0.006)^{*}$ \\
\hline \multirow[t]{2}{*}{$b_{21}$} & 0.016 & 0.021 & 0.014 & 0.020 & 0.011 & 0.015 & -0.038 & -0.036 \\
\hline & $(0.006) * * *$ & $(0.006) * * *$ & $(0.007)^{* *}$ & $(0.009)^{* *}$ & $(0.007)^{*}$ & $(0.006)^{* *}$ & $(0.023)^{*}$ & $(0.022)^{*}$ \\
\hline \multirow{2}{*}{$b_{22}$} & 0.984 & 0.985 & 0.974 & 0.972 & 0.969 & 0.976 & 0.717 & 0.715 \\
\hline & $(0.003)^{* * *}$ & $(0.003) * * *$ & $(0.004)^{* * *}$ & $(0.005)^{* * *}$ & $(0.003)^{* * *}$ & $(0.002)^{* * *}$ & $(0.031)^{* * *}$ & $(0.028) * * *$ \\
\hline \multirow[t]{2}{*}{$c u t_{11}$} & & 2.212 & & 2.103 & & 2.242 & & 1.651 \\
\hline & & $(0.476)^{* * *}$ & & $(0.423)^{* * *}$ & & $(0.497)^{* * *}$ & & $(0.413)^{* * *}$ \\
\hline \multirow[t]{2}{*}{ cut $_{12}$} & & 0.085 & & 0.012 & & 0.008 & & -0.369 \\
\hline & & $(0.143)$ & & $(0.181)$ & & $(0.127)$ & & $(0.294)$ \\
\hline \multirow[t]{2}{*}{ cut $_{22}$} & & -0.059 & & -0.169 & & -0.040 & & -0.527 \\
\hline & & $(0.176)$ & & $(0.225)$ & & $(0.142)$ & & $(0.341)$ \\
\hline \multirow[t]{2}{*}{ maintain $_{11}$} & & -1.083 & & -1.017 & & -0.578 & & -1.137 \\
\hline & & $(0.398) * * *$ & & $(0.453)^{* *}$ & & $(0.306)^{*}$ & & $(0.368)^{* * *}$ \\
\hline \multirow[t]{2}{*}{ maintain $_{12}$} & & -0.494 & & -0.280 & & -1.134 & & -1.361 \\
\hline & & $(0.119)^{* * *}$ & & $(0.231)$ & & $(0.085)^{* * *}$ & & $(0.217)^{* * *}$ \\
\hline \multirow[t]{2}{*}{ maintain $_{22}$} & & -0.059 & & -0.169 & & -0.041 & & -0.527 \\
\hline & & $(0.616)$ & & $(0.665)$ & & $(16.311)$ & & $(0.856)$ \\
\hline \multirow[t]{2}{*}{ increase $_{11}$} & & 1.147 & & 1.066 & & 1.003 & & 1.517 \\
\hline & & $(0.616)^{*}$ & & $(0.521)^{* *}$ & & $(0.681)$ & & $(0.508) * * *$ \\
\hline \multirow[t]{2}{*}{ increase $_{12}$} & & -0.214 & & 0.029 & & -0.075 & & -0.789 \\
\hline & & $(0.257)$ & & $(0.266)$ & & $(0.148)$ & & $(0.493)$ \\
\hline \multirow[t]{2}{*}{ increase $_{22}$} & & -0.058 & & -0.169 & & -0.040 & & -1.215 \\
\hline & & $(1.110)$ & & $(0.385)$ & & $(0.173)$ & & $(0.389) * * *$ \\
\hline \multicolumn{9}{|c|}{ Panel C: Diagnostic test } \\
\hline $\log L$ & -13799.890 & -13788.05 & -13961.548 & -13950.909 & -13787.273 & -13743.542 & -13269.110 & -13253.289 \\
\hline \multirow[t]{2}{*}{$H Q(20)$} & 84.894 & 84.952 & 88.583 & 86.906 & 88.189 & 91.944 & 104.547 & 108.245 \\
\hline & [0.277] & {$[0.276]$} & [0.193] & [0.229] & {$[0.201]$} & [0.133] & $.024]^{* *}$ & {$[0.013]^{* *}$} \\
\hline \multirow[t]{2}{*}{$H Q_{s}(20)$} & 116.390 & 114.260 & 94.961 & 93.910 & 90.030 & 90.939 & 116.039 & 127.341 \\
\hline & {$[0.003]^{* * *}$} & {$[0.004]^{* * *}$} & {$[0.092]^{*}$} & [0.105] & {$[0.165]$} & {$[0.150]$} & {$[0.003]^{* * *}$} & {$[0.000]^{* * *}$} \\
\hline
\end{tabular}

Notes: See notes of Table 4.

Table 11: Estimation results of VAR-DCC-GARCH model without and with OPEC news announcements (Gasoline)

\begin{tabular}{|c|c|c|c|c|c|c|c|c|}
\hline & \multicolumn{2}{|c|}{ Gasoline - Wheat } & \multicolumn{2}{|c|}{ Gasoline -Corn } & \multicolumn{2}{|c|}{ Gasoline - Sorghum } & \multicolumn{2}{|c|}{ Gasoline - Barley } \\
\hline Coef. & $\begin{array}{c}\text { without } \\
\text { OPEC news }\end{array}$ & $\begin{array}{c}\text { with OPEC } \\
\text { news }\end{array}$ & $\begin{array}{c}\text { without } \\
\text { OPEC news }\end{array}$ & $\begin{array}{c}\text { with OPEC } \\
\text { news }\end{array}$ & $\begin{array}{c}\text { without } \\
\text { OPEC news }\end{array}$ & $\begin{array}{c}\text { with OPEC } \\
\text { news }\end{array}$ & $\begin{array}{c}\text { without } \\
\text { OPEC news }\end{array}$ & $\begin{array}{c}\text { with OPEC } \\
\text { news }\end{array}$ \\
\hline \multicolumn{9}{|c|}{ Panel A: Conditional mean } \\
\hline \multirow{2}{*}{$\mu^{e}$} & 0.092 & 0.091 & 0.094 & 0.095 & 0.107 & 0.102 & 0.102 & 0.087 \\
\hline & $(0.043)^{* *}$ & $(0.044)^{* *}$ & $(0.045)^{* *}$ & $(0.043)^{* *}$ & $(0.043)^{* *}$ & $(0.044)^{* *}$ & $(0.043) * *$ & $(0.058)$ \\
\hline \multirow{2}{*}{$a^{e}$} & 0.019 & 0.017 & 0.026 & 0.024 & 0.023 & 0.023 & 0.016 & 0.011 \\
\hline & $(0.018)$ & $(0.018)$ & $(0.019)$ & $(0.018)$ & $(0.018)$ & $(0.018)$ & $(0.018)$ & $(0.025)$ \\
\hline \multirow{2}{*}{$b^{e}$} & 0.002 & 0.002 & -0.029 & -0.034 & -0.003 & -0.007 & -0.006 & -0.006 \\
\hline & $(0.028)$ & $(0.028)$ & $(0.028)$ & $(0.027)$ & $(0.027)$ & $(0.028)$ & $(0.030)$ & $(0.032)$ \\
\hline \multirow[t]{2}{*}{$c u t^{e}$} & & -0.517 & & -0.392 & & -0.219 & & -0.478 \\
\hline & & $(0.955)$ & & $(0.964)$ & & $(0.963)$ & & (1.033) \\
\hline \multirow[t]{2}{*}{ maintain $^{e}$} & & -0.209 & & -0.315 & & -0.269 & & -0.141 \\
\hline & & $(0.524)$ & & $(0.519)$ & & $(0.526)$ & & $(0.303)$ \\
\hline \multirow[t]{2}{*}{ increase $^{e}$} & & 0.477 & & 0.482 & & 0.269 & & 0.407 \\
\hline & & $(1.475)$ & & $(1.183)$ & & $(1.239)$ & & $(0.741)$ \\
\hline \multirow[t]{2}{*}{$\mu^{c}$} & 0.025 & 0.025 & 0.008 & 0.012 & 0.058 & 0.029 & 0.041 & 0.037 \\
\hline & (0.024) & $(0.024)$ & (0.027) & $(0.022)$ & $(0.023) * *$ & $(0.020)$ & $(0.013)^{* * *}$ & $(0.001)^{* * *}$ \\
\hline \multirow[t]{2}{*}{$a^{c}$} & 0.021 & 0.022 & 0.037 & 0.036 & 0.139 & 0.136 & 0.104 & 0.109 \\
\hline & $(0.018)$ & (0.018) & $(0.019) *$ & $(0.018) * *$ & $(0.020)^{* * *}$ & $(0.017) * * *$ & $(0.022)^{* * *}$ & $(0.016)^{* * *}$ \\
\hline \multirow{2}{*}{$b^{c}$} & -0.019 & -0.020 & -0.012 & -0.012 & -0.009 & -0.005 & -0.019 & -0.022 \\
\hline & $(0.008) * *$ & $(0.008)^{* * *}$ & (0.009) & (0.009) & $(0.007)$ & $(0.007)$ & $(0.005)^{* * *}$ & $(0.001)^{* * * *}$ \\
\hline cut $^{c}$ & & -0.031 & & 0.246 & & 0.107 & & -0.015 \\
\hline
\end{tabular}




\begin{tabular}{|c|c|c|c|c|c|c|c|c|}
\hline & & & & & & & & \\
\hline & & $(0.308)$ & & $(0.440)$ & & $(0.144)$ & & $(0.011)$ \\
\hline maintain $^{c}$ & & -0.037 & & 0.197 & & 0.336 & & 0.357 \\
\hline & & $(0.304)$ & & $(0.268)$ & & $(0.426)$ & & $(0.290)$ \\
\hline increase $^{c}$ & & -0.011 & & -0.758 & & -0.573 & & -0.517 \\
\hline & & $(0.450)$ & & $(0.421)^{*}$ & & $(0.453)$ & & (0.374) \\
\hline Panel B: C & nditional vari & ance & & & & & & \\
\hline$\omega^{e}$ & 0.197 & 0.239 & 0.203 & 0.251 & 0.205 & 0.257 & 0.199 & 0.233 \\
\hline & $(0.038) * * *$ & $(0.044)^{* * *}$ & $(0.059)^{* * *}$ & $(0.045)^{* * *}$ & $(0.062)^{* * *}$ & $(0.047)^{* * *}$ & $(0.038)^{* * *}$ & $(0.070)^{* * *}$ \\
\hline$\omega^{c}$ & 0.014 & 0.019 & 0.083 & 0.089 & 0.011 & 0.011 & 0.374 & 0.394 \\
\hline & $(0.003)^{* * *}$ & $(0.004)^{* * *}$ & $(0.024)^{* * *}$ & $(0.012) * * *$ & $(0.004)^{* * *}$ & $(0.003)^{* * *}$ & $(0.018)^{* * *}$ & $(0.004) * * *$ \\
\hline$\alpha^{e}$ & 0.078 & 0.079 & 0.080 & 0.082 & 0.082 & 0.084 & 0.079 & 0.077 \\
\hline & $(0.006)^{* * *}$ & $(0.006)^{* * *}$ & $(0.011)^{* * *}$ & $(0.006)^{* * *}$ & $(0.011)^{* * *}$ & $(0.006)^{* * *}$ & $(0.006)^{* * *}$ & $(0.011)^{* * *}$ \\
\hline$\alpha^{c}$ & 0.042 & 0.041 & 0.087 & 0.081 & 0.085 & 0.056 & 0.390 & 0.502 \\
\hline & $(0.005)^{* * *}$ & $(0.005)^{* * *}$ & $(0.016)^{* * *}$ & $(0.008)^{* * *}$ & $(0.010)^{* * *}$ & $(0.004)^{* * *}$ & $(0.015)^{* * *}$ & $(0.004)^{* * *}$ \\
\hline$\beta^{e}$ & 0.899 & 0.889 & 0.896 & 0.885 & 0.895 & 0.883 & 0.898 & 0.893 \\
\hline & $(0.009) * * *$ & $(0.010)^{* * *}$ & $(0.016) * * *$ & $(0.010)^{* * *}$ & $(0.016)^{* * *}$ & $(0.010)^{* * *}$ & $(0.009)^{* * *}$ & $(0.018)^{* * *}$ \\
\hline$\beta^{c}$ & 0.953 & 0.952 & 0.886 & 0.892 & 0.920 & 0.940 & 0.520 & 0.451 \\
\hline & $(0.005)^{* * *}$ & $(0.005)^{* * *}$ & $(0.022)^{* * *}$ & $(0.009)^{* * *}$ & $(0.008)^{* * *}$ & $(0.004)^{* * *}$ & $(0.015)^{* * *}$ & $(0.003)^{* * *}$ \\
\hline$c u t^{e}$ & & 5.544 & & 5.973 & & 6.045 & & 5.111 \\
\hline & & $(2.504) * *$ & & $(2.633)^{* *}$ & & $(2.637)^{* *}$ & & $(2.607)^{* *}$ \\
\hline$c u t^{c}$ & & -0.489 & & -0.894 & & -0.461 & & -0.729 \\
\hline & & $(0.131)^{* * * *}$ & & $(0.184)^{* * *}$ & & $(0.054) * * *$ & & $(0.003)^{* * *}$ \\
\hline maintain $^{e}$ & & -0.377 & & -0.420 & & -0.377 & & -0.521 \\
\hline & & $(0.702)$ & & $(0.711)$ & & $(0.728)$ & & (0.699) \\
\hline maintain $^{c}$ & & 0.065 & & -0.198 & & 0.970 & & 0.665 \\
\hline & & $(0.136)$ & & $(0.211)$ & & $(0.104) * * *$ & & $(0.315)^{* *}$ \\
\hline increase $^{e}$ & & 1.871 & & 1.382 & & 1.301 & & 1.222 \\
\hline & & (1.292) & & (1.332) & & (1.282) & & $(0.900)$ \\
\hline increase $^{c}$ & & -0.140 & & -0.456 & & -0.264 & & 0.396 \\
\hline & & $(0.182)$ & & $(0.303)$ & & $(0.118)^{* *}$ & & $(0.292)$ \\
\hline Panel C: C & relation & & & & & & & \\
\hline$\kappa_{1}$ & 0.062 & 0.062 & 0.008 & 0.008 & 0.024 & 0.025 & 0.011 & 0.010 \\
\hline $\mathbf{n}_{1}$ & $(0.022)^{* * *}$ & $(0.022)^{* * *}$ & $(0.003)^{* * *}$ & $(0.003) * * *$ & $(0.018)$ & $(0.018)$ & $(0.005) * *$ & $(0.004) * *$ \\
\hline$\kappa$ & 0.137 & 0.146 & 0.989 & 0.989 & 0.227 & 0.291 & 0.986 & 0.987 \\
\hline & $(0.304)$ & $(0.304)$ & $(0.005)^{* * *}$ & $(0.004)^{* * *}$ & $(0.351)$ & $(0.542)$ & $(0.007)^{* * *}$ & $(0.007) * * *$ \\
\hline Panel D: D & agnostic test & & & & & & & \\
\hline $\log L$ & -13797.191 & -13786.841 & -13937.333 & -13925.472 & -13767.116 & -13719.601 & -13242.271 & -13223.93 \\
\hline$H Q(20)$ & 84.333 & 84.711 & 87.964 & 86.487 & 87.960 & 89.985 & 106.560 & 112.749 \\
\hline & [0.292] & [0.282] & [0.206] & [0.239] & [0.206] & [0.166] & {$[0.017]^{* *}$} & {$[0.006]^{* * *}$} \\
\hline$H Q_{s}(20)$ & 104.568 & 103.298 & 80.806 & 80.283 & 74.284 & 77.257 & 81.693 & 83.178 \\
\hline & {$[0.024]^{* *}$} & {$[0.029]^{* *}$} & [0.391] & {$[0.407]$} & {$[0.598]$} & {$[0.502]$} & {$[0.365]$} & {$[0.323]$} \\
\hline
\end{tabular}

Notes: See notes of Table 4.

Summarizing all, our results point to the presence of widespread direct spillovers of shocks and volatility between oil and cereal markets. They also indicate that the volatility persistence of the oil markets deceases over time with the exception of gasoline, while for cereal markets the results are rather mixed. The impacts of the OPEC news announcements on information transmission between oil and cereal markets differ remarkably according to the production decisions (maintain, increase, and cut) that have been made. More importantly, the ability of commodity markets to absorb these news announcements differs from a market to another. The reaction and anticipation of global investors, traders, and speculators to the OPEC decisions are asymmetric. For instance, the cut decisions have a much larger effect on the volatility spillover than the decisions to maintain or increase the current output. 
The observed link between oil and cereal markets can be explained by the surge in production of biofuel since 2006. The production of the bioethanol comes from corn while that of biodiesel is extracted from soybeans. These biofuels are considered as substitutes for conventional fuels such as diesel and gasoline (Chang and $\mathrm{Su}, 2010)$. The appreciation and depreciation of exchange rates also play a crucial role on the determination of the direction and the origins of volatility transmission between oil and agricultural prices (e.g., Abbott et al., 2008, 2009; Cooke and Robles, 2009; Harri et al., 2009; Nazlioglu and Soytas, 2011). Furthermore, agricultural and oil commodities are generally traded in US dollars and that the exchange rate changes are one of the important item of the 2007-2008 food crisis. Accordingly, participants in each market seeking profit from trading oil and cereal assets may consider active investment strategies based on a joint volatility transmission and current market trends. Risk-averse investors apply the strategy of international portfolio diversification, and their portfolios may be composed of both oil and agricultural assets. For all these strategies, the diversified portfolios' optimal weights and hedging ratios can be straightforwardly computed from the estimates of our empirical models. ${ }^{11}$

Further economic explanations can be obtained from our empirical results. First, the oil-cereal relationship has important fiscal and monetary policy implications. The low interest rates in the United States explain the increasing commodity prices. Also, the BRICS (Brazil, Russia, China, India and South Africa)'s fast economic growth rates, especially those of China and India, lead to high growth demand for energy which is accompanied by increases in agricultural commodity prices. The instability in the supply of oil and the presence of OPEC's interventions are crucial factors that underline the variations in economic fundamentals and more importantly the patterns of commodity prices. Monetary expansions as measured by world real money supply are of great significance for commodity price spikes (Gilbert, 2010).

\section{Conclusion}

Past empirical studies have shown that both the oil and cereal markets are currently characterized by high volatility and that they have become more interrelated. Thus, understanding the comovement between these markets as well as their potential volatility spillovers

\footnotetext{
${ }^{11}$ Since in this paper we do not focus on the portfolio designs, the interested readers can refer to Arouri et al. (2011) for the computational aspects of optimal weights and hedging ratios. However, the empirical results regarding these portfolio weights and hedge ratios can be made available upon request to the corresponding author.
} 
is of particular importance for many economic agents including market operators and policymakers. In this study, we have attempted to address this issue by quantifying the dynamic spillovers of the return volatility and shocks among four oil-related markets (WTI, Brent, heating oil, and gasoline) and four cereal markets (wheat, corn, sorghum and barley). Our second objective is to examine whether the OPEC production announcements have significant impacts on these return and volatility spillovers.

At the empirical level, we employ two frequently-used multivariate GARCH models including the BEKK-GARCH of Engle and Kroner (1995), and the DCC-GARCH of Engle (2002). The obtained results show that these empirical models are flexible enough to capture the dynamic structure of the return interactions, volatility spillovers, and conditional correlations. They also provide evidence of significant information transmission across the different markets under consideration over the period from January 4, 2000 to January 29, 2013. In particular, we find bidirectional effects across barley and each of the crude oil and gasoline markets. All commodity assets, except for the gasoline and sorghum markets, have been driven by dynamic conditional correlations with common increasing tendency during the last global financial crisis. This evidence suggests that a dynamic risk management approach (e.g., Value-at-Risk) should be implemented in order to take into account the joint dynamics of these markets.

The impact of the OPEC news announcements on the return and volatility spillovers is then discussed by incorporating them into our bivariate VAR-BEKK-GARCH and VARDCC-GARCH models as dummy variables. We find that the OPEC production decisions have a significant impact on volatility of the oil and cereal commodity markets. The cut decisions have a much larger effect on both types of commodity markets than the decisions to increase and to maintain the current production levels. These findings remain intact for both empirical models we consider, suggesting that the markets under consideration react asymmetrically to the OPEC production decisions. These markets also seem to absorb these news announcements in a different way and consider the cut decisions as bad news and increase/maintain decisions as good news. We then support the effect of OPEC news announcements as influential asymmetric market signals.

Overall, our results have important implications for forecasting the future oil and cereal return volatility, making optimal portfolio allocation decisions, energy traders, and farmers. One can easily compute, based on our models' estimates, the optimal weights and hedging ratios for portfolios of oil and cereal assets, and investigate the diversification and hedg- 
ing effectiveness. Several studies have dealt with these issues in the past literature (e.g., Arouri et al., 2011; Chang et al., 2011).

It will be intriguing to extend this study in future research in at least two directions: (1) investigating the role of the growing biofuels (e.g., corn-based ethanol production and soybean-based biodiesel production), relevant economic and financial variables (e.g., inflation, term structure of interest rate, speculation, and the US dollar index) as exogenous shocks on the dynamic spillovers across oil and cereal prices; and (2) examining the asymmetric effects, i.e., using the Asymmetric DCC-MGARCH model to investigate the relationships between the oil and cereal markets in face of positive and negative shocks.

\section{References}

Abbott, P.C., Hurt, C., Tyner, W.E., 2008. What's driving food prices? Farm Foundation Issue Report, July 2008.

Abbott, P.C., Hurt, C., Tyner, W.E., 2009. What's Driving Food Prices? Farm Foundation Issue Report. March 2009 update.

Arouri, M., Jouini, J., Nguyen, D.K., 2011. Volatility spillovers between oil prices and stock sector returns: implications for portfolio management. Journal of International Money and Finance 30, 1387-1405.

Baffes, J., 2011. The energy/non-energy price link: Channels, issues, and implications. In I. Piot-Lepetit, ed., Methods to Analyse Agricultural Commodity Price Volatility, New York: Springer, 31-44.

Bauwens, L., Laurent, S., Rombouts, J.V. K., 2006. Multivariate GARCH models: A survey. Journal of Applied Econometrics 21, 79-109.

Benson, T., Minot, N., Pender, J., Robles, M., Braun, J.V., 2013. Information to guide policy responses to higher global food prices: The data and analyses required. Food Policy 38, 47-58.

Bina, C., Vo, M., 2007. OPEC in the epoch of globalization: an event study of global oil 802 prices. Global Economic Journal 7, 1-49.

Campiche, J.L., Bryant, H.L., Richardson, J.W., Outlaw, J.L., 2007. Examining the evolving correspondence between petroleum prices and agricultural commodity prices. The American Agricultural Economics Association Annual Meeting, Portland, OR, July 29-August 1, 2007.

Caporin, M., McAleer, M., 2009. Do we really need both BEKK and DCC? A tale of two covariance models. Discussion Paper No. 738, Kyoto Institute of Economic Research.

Chang, C., McAleer, M., Tansuchat, R., 2011. Crude oil hedging strategies using dynamic multivariate GARCH. Energy Economics 33, 912-923.

Chang, T., Su, H., 2010. The substitutive effect of biofuels on fossil fuels in the lower and higher crude oil price periods. Energy 35, 2807-2813.

Chen, S.T., Kuo, H.I., Chen, C.C., 2010. Modeling the relationship between the oil price and global food prices. Applied Energy 87, 2517-2525.

Comte, F., Lieberman, O., 2003. Asymptotic theory for multivariate GARCH processes. Journal of Multivariate Analysis 84, 61-84.

Cooke, B., Robles, M., 2009. Recent food price movements: A time series analysis. IFPRI Discussion Paper, No.00942. IFPRI, Washington, DC.

Creti, A., Joëts, M., Mignon, V., 2013. On the links between stock and commodity markets' volatility. Energy Economics 37, 16-28. 
Deaves, R.I., Krinsky, I., 1992. The behaviour of oil futures returns around OPEC conferences. Journal of Futures Markets 12, 563-574.

Demirer, R., Kutan, A.M., 2010. The behavior of crude oil spot and futures prices around OPEC and SPR announcements: An event study perspective. Energy Economics 32, 1467-1476.

Dickey, D., Fuller, W., 1979. Distribution of the estimators for autoregressive time series witha unit root. Journal of the American Statistical Association 74, 427-431.

Ding, Z., Engle, R.F., 2001. Large scale conditional covariance matrix modeling, estimation and testing. Academia Economic Papers 29, 157-184.

Du, X., Yu, C.L., Hayes, D.J., 2011. Speculation and volatility spillover in the crude oil and agricultural commodity markets: A Bayesian analysis. Energy Economics 33, 497-503.

Engle, R.F., 2002. Dynamic conditional correlation: A simple class of multivariate generalized autoregressive conditional heteroskedasticity models. Journal of Business \& Economic Statistics 20, 339-350.

Engle, R.F., Kroner, K.F. 1995. Multivariate simultaneous generalized ARCH. Econometric Theory 11, $122-150$.

FAO, 2008. Soaring food prices: facts, perspectives, impacts and actions required. In: Proceedings of the HighLevel Conference on World Food Security, Rome, 3-5 June 2008.

Gardebroek, C., Hernandez, M.A., 2013. Do energy prices stimulate food price volatility? Examining volatility transmission between US oil, ethanol and corn markets. Energy Economics 40, 119-129.

Gilbert, C.L., 2010. How to understand high food prices. Journal of Agricultural Economics 61, 398-425.

Gilbert, C.L., Morgan, C.W., 2010. Food price volatility. Philosophical Transactions of the Royal Society of London. Series B: Biological Sciences 365, 3023-3034.

Granger, C.W.J., 1969. Investigating causal relations by econometric models and cross-spectral methods. Econometrica $37,424-438$.

Hafner, C.M., Herwartz, H., 2006. A Lagrange multiplier test for causality in variance. Economics Letters 93, 137-141.

Hammoudeh, S., Chang, C-L., Chen, L-H., McAleer, M., 2012. Asymmetric adjustments in the ethanol and grains markets. Energy Economics34, 1990-2002.

Hammoudeh, S., Yuan, Y., McAleer, M., 2009. Shock and volatility spillovers among equity sectors of the Gulf Arab stock markets. Quarterly Review of Economics and Finance 49, 829-842.

Hanson, K., Robinson, S., Schluter, G., 1993. Sectoral effects of a world oil price shock: economy wide linkages to the agricultural sector. Journal of Agricultural and Resource Economics 18, 96-116.

Harri, A., Nalley, L., Hudson, D., 2009. The relationship between oil, exchange rates, and commodity prices. Journal of Agricultural and Applied Economics 41, 501-510.

Hosking, J.R.M., 1980. The multivariate portmanteau statistic. Journal of the American Statistical Association $75,602-608$.

Jeantheau, T. 1998. Strong consistency of estimators for multivariate ARCH models. Econometrics Theory 14, 70-86.

Ji, Q., Fan, Y. 2012. How does oil price volatility affect non-energy commodity markets? Applied Energy 89, 273-280.

Kwiatkowski, D., Phillips, P.C.B., Schmidt, P., Shim, Y., 1992. Testing the null hypothesis of stationarity against the alternative of a unit root: how sure are we that economic time series are non-stationary? Journal of Econometrics 54, 159-178.

Kym, A., Signe, N., 2012. Trade barrier volatility and agricultural price stabilization. World Development 40, 36-48.

Ling, S., McAleer, M., 2003.Asymptotic theory for a vector ARMA-GARCH model. Econometric Theory 19, 278-308.

Manera, M., Nicolini, M.,Vignati, I., 2012. Returns in commodities futures markets and financial speculation: A multivariate GARCH approach. FEEM Working Paper No. 23. 
Martine, R., Lindsay, S., Gerdien, M., 2013. Sit down at the ball game: How trade barriers make the world less food secure. Food Policy 38, 1-10.

Mensi, W., Beljid, M., Boubaker, A., Managi, S., 2013. Correlations and volatility spillovers across commodity and stock markets: Linking energies, food, and gold. Economic Modelling 32, 15-22.

Mitchell, D., 2008. A note on rising food prices. World Bank Policy Research Working Paper Series No. 4682.

Nazlioglu, S., 2011. World oil and agricultural commodity prices: Evidence from nonlinear causality. Energy Policy 39, 2935-2943.

Nazlioglu, S., Erdem, C., Soytas, U., 2013. Volatility spillover between oil and agricultural commodity markets. Energy Economics 34, 658-665.

Nazlioglu, S., Soytas, U., 2011. World oil prices and agricultural commodity prices: Evidence from an emerging market. Energy Economics 33, 488-496.

Philips, P.C.B., Perron, P., 1988. Testing for unit roots in time series regression. Biometrika75, 335-346.

Reboredo, J.C., 2012. Do food and oil prices co-move? Energy Policy 49, 456-467.

Richards, T.J., Allender, W.J., Hamilton, S.F., 2012. Commodity price inflation, retail pass-through and market power. International Journal of Industrial Organization 30, 50-57.

Sari, R., Hammoudeh, S., Chang, C.L., McAleer, M., 2012. Causality between market liquidity and depth for energy and grains. Energy Economics 34, 1683-1692.

Schmidbauer, H., Rösch, A., 2012. OPEC news announcements: Effects on oil price expectation and volatility. Energy Economics 34, 1656-1663.

Serra, T., 2011. Volatility spillovers between food and energy markets: A semi parametric approach. Energy Economics 33, 1155-1164.

Sumner, D.A., 2009. Recent commodity price movements in historical perspective. American Journal of Agricultural Economics 91, 1250-1256.

Vivian, A., Wohar, M.E., 2012. Commodity volatility breaks. Journal of International Financial Markets, Institutions and Money 22, 395-422.

Von Braun, J., 2008. Rising food prices: what should be done? International Food Policy Research Institute IFPRI.

Wirl, F., Kujundzic, A., 2004. The impact of OPEC conference outcomes on world oil prices 1984-2001. Energy Journal 25, 45-62.

Wright, B.D., 2011. The economics of grain price volatility. Applied Economic Perspectives and Policy 33, 3258.

Wu, H., Li, S., 2013. Volatility spillovers in China's crude oil, corn and fuel ethanol markets. Energy Policy 62, 878-886.

Zhang, Z., Lohr, L., Escalante, C., Wetzstein, M., 2010. Food versus fuel: what do prices tell us? Energy Policy $38,445-4451$.

Zhang, Q., Reed, M., 2008. Examining the impact of the world crude oil price on China's agricultural commodity prices: the case of corn, soybean, and pork. In: Proceedings of the Southern Agricultural Economics Association Annual Meetings, Dallas, TX, February 2-5, 2008. 